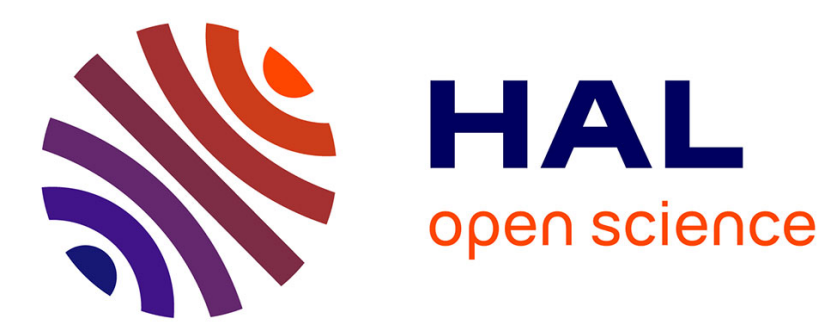

\title{
Surfactant-Templating of Zeolites: From Design to Application
}

\author{
Alexander Sachse, J Garcia Martinez
}

\section{To cite this version:}

Alexander Sachse, J Garcia Martinez. Surfactant-Templating of Zeolites: From Design to Application. Chemistry of Materials, 2017, 29 (9), pp.3827-3853. 10.1021/acs.chemmater.7b00599 . hal-03033514

\section{HAL Id: hal-03033514 https://hal.science/hal-03033514}

Submitted on 1 Dec 2020

HAL is a multi-disciplinary open access archive for the deposit and dissemination of scientific research documents, whether they are published or not. The documents may come from teaching and research institutions in France or abroad, or from public or private research centers.
L'archive ouverte pluridisciplinaire HAL, est destinée au dépôt et à la diffusion de documents scientifiques de niveau recherche, publiés ou non, émanant des établissements d'enseignement et de recherche français ou étrangers, des laboratoires publics ou privés. 


\title{
Surfactant-Templating of Zeolites: From Design to Application
}

A. Sachse $e^{1}$ and J. Garcia Martinez ${ }^{1,2} *$

${ }^{1}$ Dr. A. Sachse, Molecular Nanotechnology Lab, Department of Inorganic Chemistry, University of Alicante, E-03080 Alicante, Spain.

${ }^{2}$ Dr. J. Garcia Martinez, Molecular Nanotechnology Lab, Department of Inorganic Chemistry, University of Alicante, E-03080 Alicante, Spain.

Rive Technology, Inc., 1 Deer Park Drive, Monmouth Junction, NJ 08852, USA.

*E-mail: j.garcia@ua.es

\begin{abstract}
Surfactant-templating is one of the most effective and versatile synthetic strategies for the construction of well-defined porous architectures in solids. Though the principles of molecular self-assembly were disclosed in biological systems since long, the use of amphiphiles to generate porous architectures in inorganic matter has merely emerged at the very end of the $20^{\text {th }}$ century. The present review proposes a voyage from the early developments of surfactanttemplating for designing ordered mesoporous solids to the application of its principles for the generation of hierarchical zeolites. A thorough overview on the various strategies employing supramolecular chemistry to designing mesoporosity in zeolites is presented. The efficiency of the post-synthetic surfactant-templating approach in bridging the gap between zeolites and amorphous mesoporous molecular sieves is depicted through assessing their key properties, such as hydrothermal stability, texture, and acidity. Finally, the impact of hierarchical zeolites in the industry will be highlighted through a review of the catalytic performance of mesostructured zeolites as components of FCC catalysts in various refineries.
\end{abstract}




\section{Surfactant-templating: A unique toolbox for the design of mesoporous materials}

Surfactant-templating (also referred as supramolecular templating) emerged as general term to describe the chimie douce approaches for conceiving solids with tunable porosity. These soft chemistry strategies in materials design comprise the evolution of porous features, determined by supramolecular assemblies that act as templates, which develop from individual amphiphilic molecules, i.e. surfactants. Surfactant-templating might indeed be defined as: a synthetic strategy leading to materials featuring tailored porosity, both in terms of pore size and architecture, by employing the self-assembly properties of surfactant molecules, which act as porogen, and their interactions with moieties of the forming material. At present, surfactant-templating has established as a versatile strategy especially suited for the preparation of well-defined porous materials of various chemical natures typically in the mesopores range organized in a variety of architectures.

Though the principle of surfactant-templating was firstly applied in 1969 for the achievement of mesostructured amorphous silica using trimethylalkylammoniumbased amphiphilic molecules, it was not until more than 20 years later that the potential of this strategy was realized, possibly due to the lack of appropriate characterization of the developed material. ${ }^{[1,2]}$ In 1990 Yanagisawa et al. ${ }^{[3]}$ reported the achievement of surfactant-templated silica by exposing kanemite to trimethylalkylammonium-based surfactants at basic $\mathrm{pH}$. The authors observed the development of several peaks in the low angle XRD region, ascribable to the formation of an ordered mesoporous network in the silica material. Further, they observed the size-dependency of the developed porosity as a function of the length of the hydrocarbon chain of the surfactant, which is a characteristic feature of surfactant-templating. Yet, it was only through the famous publication by Mobil Oil scientists in 1992 that surfactant-templating embarked in its amazing success story for the design of tailored porous materials. ${ }^{[4,5]}$ Therein the authors described the achievement of three mesoporous silica materials featuring porous architectures of different space groups, today known as M41S family. This class of ordered mesoporous materials undoubtedly epitomizes the versatility of the surfactant-templating approach for the development of mesoporous architectures with extremely narrow and tunable pore size. ${ }^{[6]}$

These early developments gave rise to the evolvement of a new field in materials chemistry and served as inspiration for the design of a plethora of mesoporous 
materials of well-defined architectures. Promptly the principles of surfactanttemplating were applied for the design of a great variety of metal oxides based on magnesium, aluminum, manganese, iron, cobalt, nickel, zinc, tungsten, as well as of non-oxide compounds, such as phosphates, sulfides, nitrides, carbides and selenides by judiciously selecting the appropriate surfactants and adjusting the synthesis conditions. ${ }^{[7-11]}$ These advancements went hand in hand with the development of a diversity of synthetic strategies based on the use of charged (cationic or anionic salts) and non-ionic surfactants in a wide range of $\mathrm{pH}$ conditions. A detailed description of the choice of surfactants and synthesis conditions for the achievement of different mesophases has been outlined in the excellent review by Wan and Zhao. ${ }^{[9]}$

A variety of assembly mechanisms have been disclosed attending to the nature of the employed surfactant and to the synthetic conditions (particularly the $\mathrm{pH}$ ). A charge matching model was developed by Huo et al., ${ }^{[10]}$ who introduced a specific nomenclature to describe the synthetic path leading to the mesostructured material. When employing ionic surfactants, the development of the mesophase is essentially governed by columbic interactions, which is the case when either the surfactant (S) or the inorganic species (I) are oppositely charged. The two possibilities hereto are the $\mathrm{S}^{+} \mathrm{I}^{-}$or $\mathrm{S}^{-} \mathrm{I}^{+}$paths. When synthetic conditions are chosen in such a way that both inorganic moieties and the surfactant molecules present the same charge, anions (X) or cations (M) present in the solution participate in the structuration process. The resulting mechanisms can be described as to follow $\mathrm{S}^{+} \mathrm{X}^{-} \mathrm{I}^{+}$or $\mathrm{S}^{-} \mathrm{M}^{+} \mathrm{I}^{-}$paths. In the case non-ionic surfactants are employed, the path can be described as $\mathrm{S}^{0} \mathrm{I}^{0}$ and is based on hydrogen bond or dipolar interactions. The latter is often denominated $\mathrm{N}^{0} \mathrm{I}^{0}$ when amines $(\mathrm{N})$ are used as surfactants. Soler-Illia et al. were the first to propose to schematically represent these pathways as a function of the chemical interactions (Figure 1A). ${ }^{[11]}$

It is the hydrophilic - hydrophobic interactions between the surfactant and the solvent (in most cases water) that are the driving force for the assembly into various micellar shapes of thermodynamically stable phases giving rise to mesostructures of different architectures with long range order. The micellar packing parameter is particularly useful to predict the achieved mesophase in the case ionic surfactants are employed (Figure 1B). ${ }^{[12]}$ Important evidence has been 
produced that in the mesostructuration employing non-ionic surfactants the mesophase is determined by the hydrophilic/hydrophobic volume ration $\left(\mathrm{V}_{\mathrm{H}} / \mathrm{V}_{\mathrm{L}}\right)$ of the surfactant. ${ }^{[13,14]}$

The principles of surfactant-templating could further be applied to the synthesis of periodic mesoporous carbons. In this case, most approaches rely on the $\mathrm{S}^{0} \mathrm{I}^{0}$ path by employing non-ionic surfactants. Indeed, it is the hydrogen bridges that form between the phenolic resins (used as carbon source) and the block copolymers that lead to mesostructuration. Here surfactants are removed by extraction and final carbonization of the mesoporous polymer leads to the mesoporous carbon material. This strategy was recently reviewed by Ma et al. ${ }^{[15]}$ In 2008, surfactant-templating was further adapted to produce a new class of hierarchical organic-inorganic hybrid materials described as mesostructured metal organic frameworks (meso-MOFs). ${ }^{[16]}$ Lately, Bradshaw et al. ${ }^{[17]}$ reviewed the different strategies based on supramolecular assembly of amphiphiles for the achievement of the mesoporous hybrid materials.

Thanks to the knowledge gained in the design of a wide variety of porous amorphous solids (Fig 1C), a handful of strategies based on surfactant-templating have emerged to produce hierarchical crystalline materials and in particular for conceiving mesoporosity in zeolites. These approaches are particularly stimulated by the long-standing goal to finally bridge the gap between mesoporous materials and zeolites. The application of surfactant-templating for the development of hierarchical zeolites has emerged as a set of extremely promising techniques that up to date constitute the sole possibility to truly tailor mesoporosity in zeolites. These strategies will be highlighted in the following sections.

\section{The need for surfactant-oriented strategies for the conception of hierarchical zeolites}

The development of ordered mesoporous inorganic materials, and in particular aluminosilicates, created very high expectations in the early 1990s as many researchers believed that this new class of porous materials would revolutionize chemical industry, and especially replace the use of zeolites in processing bulky hydrocarbons. Yet, it soon became clear that the achieved materials present major drawbacks, especially related with their weak acidity and poor hydrothermal stability. ${ }^{[18]}$ 
It was soon pointed out that the ideal material should contain the advantages of both zeolites (strong acidity and excellent hydrothermal stability) and mesoporous molecular sieves (high accessibility of reactant molecules to active sites and fast diffusion of product molecules out of the catalyst), through the development of mesoporous materials with zeolitic pore walls. ${ }^{[19]}$ This powerful image has been the driving force for the development of hierarchical zeolites for over two decades.

With the aim to realize the depicted materials class, researchers initially developed an approach that relied on the direct crystallization of amorphous mesoporous materials (e.g. MCM-41). ${ }^{[20]}$ This strategy proved highly unsuccessful and up to date, there is no report claiming the complete crystallization of the mesoporous skeleton of periodic porous amorphous materials. ${ }^{[21,22]}$ It has later been indicated that the zeolite lattice is incompatible with the mesoporous curvature and it is thus that these approaches lead to partial or total loss of the textural mesoporous properties of the original silica. Yet, this limitation was overcome through the crystallization of SBA-15/CMK-5 composites by the treatment with tetrapropylammonium hydroxide (TPAOH). Here, the carbon mold acts as scaffold allowing for maintaining the mesoporosity even after complete zeolitization of the amorphous silica. ${ }^{[23]}$

Various strategies, which do not require the use of surfactants have been put forward with the aim of achieving hierarchical zeolites. ${ }^{[24-30]}$ A very first strategy aiming at conceiving mesoporosity in zeolites was based on creating cavities through the dissolution of alumina or silica species from the zeolite framework. Indeed the formation of secondary porosity in zeolites can readily be achieved through simple treatment of the solids with bases, acids or steam. Though rather simple and cost efficient, these strategies produce uncontrolled porosity that often is not connected in the zeolite crystals. The forming secondary porosity can hardly be tuned and defined porous architectures cannot be achieved by these means. These techniques feature the additional inconvenience that the nature and strength of the acid sites are altered during the treatment and the integrity of the zeolite is damaged.

Additionally, the hard-templating approach was developed for the conception of mesoporous zeolites and firstly reported through the use of carbon nanoparticles within the synthesis gel. ${ }^{[31]}$ An important variety of hard templates have been 
investigated for this approach, such as carbon nanotubes or nanofibers, mesoporous carbons and carbon aerogels. This approach yet presents important drawbacks, chiefly the high cost of sacrificial templates. ${ }^{[32]}$

In contrast to the aforementioned approaches, surfactant-oriented strategies present a much higher degree of flexibility and permit to achieve tailored textural properties and a variety of architectures based on the nature of the amphiphiles and their interaction with the zeolitic species. In the following sections, we will consider the variety of surfactant-oriented approaches that have been disclosed in the recent scientific literature with specific focus on the nature of the interactions between surfactant and the inorganic species.

\section{Surfactant-oriented strategies for achieving mesoporous zeolites}

\subsection{Double or dual templating}

Moved by the explosive development of surfactant-templating for the conception of mesoporous inorganic materials, researchers attempted to directly transpose this synthetic strategy to the design of mesoporous zeolites. The surfactant is added right from the beginning to the zeolite synthesis gel composition that, depending on the target zeolite phase, is usually composed of a silica and alumina source in basic $\mathrm{pH}$ with the eventual employment of zeolites structure directing agents (SDA). This process is hence frequently referred as dual or double templating as the surfactants and the zeolite SDA are simultaneously present in the zeolite synthesis solution.

Very few of these attempts have revealed fruitful, as in most cases, phase segregation is the leading process; yielding a purely microporous and mesoporous phase. Kloetstrat et al. ${ }^{[33]}$ were the first to observe the formation of two distinct phases by adding cetyltrimethylammonium chloride (CTAC, $\left.\left(\mathrm{CH}_{3}\right)_{3} \mathrm{NC}_{16} \mathrm{H}_{33} \mathrm{Cl}\right)$ directly to the synthesis gel of zeolite $\mathrm{Y}$. The authors reported the achievement of 1 micron sized zeolite $\mathrm{Y}$ crystals, overgrown with a thin layer of amorphous MCM-41. Later, Karlsson et al. ${ }^{[34]}$ described the double templating approach for MFI materials employing trimethylalkylammonium-based surfactants. Aware that the MFI phase requires high crystallization temperatures whilst mesoporous phases can readily be obtained at room temperature, they implemented multi-step treatments at various temperatures and using different surfactant to SDA ratios. 
The authors concluded that both templates act in competitive manner, invariably yielding two distinct phases.

Numerous reasons have been put forward aiming at explaining the unsuitability of such approaches in attaining truly hierarchical zeolites. From a synthetic point of view, zeolite crystallization and mesophase formation feature very different mechanisms and kinetics. Whilst periodic mesostructures of amorphous solids usually form fast and at low temperatures, zeolite synthesis requires longer crystallization times and often hydrothermal conditions.

Interestingly, Du et al. ${ }^{[35]}$ reported very recently the achievement of the hierarchical titanosilicate TS-1 featuring intracrystalline mesoporosity through the employment of the non-ionic surfactant Triton X-100 (polyethylene glycol tert-octylphenyl ether) simultaneously to the zeolite SDA tetrapropylammonium hydroxide (TPAOH). The obtained TS-1 crystals were smaller in size than the reference microporous TS-1 achieved in the absence of the surfactant and featured wide size distribution of mesopores with mesoporous volumes of up to $0.17 \mathrm{~cm}^{3} \mathrm{~g}^{-1}$. Yet, the development of a wide size distribution of mesopores is a strong indication that the surfactant-templating was not very effective.

\subsubsection{The effect of polymers and polymer/surfactants in the dual synthesis} approach

Direct synthesis approaches based on the use of employing charged high molecular weight polymers have further been described. Such polymers cannot strictly be defined as surfactants due to their inability to form supramolecular assemblies through self-assembly. ${ }^{[36]}$ Yet, the formation of the mesophase relies on a soft-templating approach and on the efficient interactions of the positive surface charge of the polymers with the forming zeolite species in the synthesis gel.

The first to explore this synthesis route were Xiao et al. ${ }^{[36,37]}$ who added polydiallyldimethylammonium chloride (PDADMAC) to the synthesis gel of zeolite *BEA. The authors reported the synthesis of a zeolite featuring disordered intracrystalline mesoporosity presenting a wide size distribution. The intracrystalline nature of the mesoporosity was assessed through electron diffraction tomography (EDT) that allows for the three-dimensional (3-D) reciprocal space reconstruction of the crystals. This reconstruction rendered a part of the reciprocal lattice of the framework of the zeolite *BEA and represents by 
projections along $\mathrm{a}^{*}, \mathrm{~b}^{*}$ and $\mathrm{c}^{*}$ axes of the crystal. The authors furthermore highlighted the fact that the reflections along the $b^{*}$ plane were elongated which would suggest a certain degree of structural disorder of the crystal lattice which can readily be attributed to the presence of highly dense mesopores (Figure 2). Additionally, high angle annular dark field scanning transmission electron microscopy (HAADF-STEM) further allowed for imaging the crystalline nanostructure containing three-dimensionally interconnected mesoporosity of high density in the entire crystal.

The same group reported the achievement of mesoporous ZSM-5 by the use of polystyrene-co-4-polyvinylpyridine (C-PSt-co-P4VP) previously treated with methyl iodide directly in the synthesis mixture. ${ }^{[38]}$ ZSM-5 crystals featuring intracrystalline mesoporosity aligned along the b-axis of the zeolite crystallinity were achieved. Yet, mesoporosity is not well-defined and its size distribution covers the entire mesoporous range.

Liu et $a l .{ }^{[39]}$ succeeded in synthetizing mesoporous MFI zeolites of various Si/Al ratios by the use of the anionic polymer poly(acrylic acid) in combination with the cationic surfactant CTAB and the zeolite SDA TPAOH. The authors reported that the use of the negatively charged polymer does not allow for the formation of hierarchical zeolite with MFI structure. Yet, by the addition of the cationic surfactant, a polymer-surfactant complex develops where the negative charge density of the polymer is efficiently reduced allowing the electrostatic attraction of the organic template with the negatively charged inorganic species. Hence, MFI type zeolites with mesopores in the range of 5-20 $\mathrm{nm}$ were achieved.

The group of Pinnavaia ${ }^{[40]}$ developed polymers with the ability to covalently bind to the forming inorganic zeolite network. The group designed silylated polyethylamines able to connect to the inorganic species through hydrolysis and condensation. This strategy yielded mesoporous ZSM-5 (named MSU-MFI), which presents a well-defined capillary condensation regime in the nitrogen physisorption isotherm. The textural properties of the achieved MSU-MFI could be further modulated by altering the molecular weight of the polymer. 


\subsubsection{Combining zeolite seeds and surfactants: amorphous mesoporous materials with}

zeolite characteristics

An alternative to the direct synthesis approach is the use of nanosized zeolites socalled "zeolite seeds" as precursors of the crystalline phase through their combination with surfactants during the hydrothermal treatments (Figure 3A). Such nanosized zeolites are usually synthesized through classical zeolite synthesis conditions but at shorter synthesis times and often lower temperatures. These seeds show no X-ray diffraction peaks; yet typical vibrational bands ascribable to the zeolite phase are observable by IR and Raman spectroscopy, which indicates the existence of small zeolite units but the absence of long-range crystallinity (Figure 3B). ${ }^{[41]}$

Inspired by the insights disclosed for the synthesis of the M41S family, the group of Pinnavaia was the first to investigate the use of protozeolitic species in combination with the cationic ammonium-based surfactant, namely CTAB ${ }^{[42]}$ They prepared zeolite Y seeds with a Si/Al ratio of 9 , lowered the $\mathrm{pH}$ of the seed solution to 9 and then added an aqueous surfactant solution prior to aging the mixture at $100{ }^{\circ} \mathrm{C}$ for $20 \mathrm{~h}$. Through this approach, a material composed of a single phase (Al-MSU-S) presented hexagonally ordered mesopores, yet they lacked zeolite crystallinity as determined by $\mathrm{X}$-ray diffraction (Figure 3C). Nonetheless, from their careful characterization through ${ }^{27} \mathrm{Al}$ MAS NMR, the retention of a zeolite-like connectivity of the $\mathrm{AlO}_{4}$ tetrahedra upon the assembly of the mesostructure could be deduced, which was taken as evidence of the presence of a FAU local structure within the mesopore walls. The authors evidenced moreover the superior hydrothermal stability and improved cumene cracking activity of the Al-MSU-S materials compared to Al-MCM-41 with equal Si/Al ratio, which was taken as further proof of the presence of zeolite fragments within the pore walls of the mesoporous structure.

The same research group expanded this approach by using MFI and BEA zeolite seeds to obtain MSU-S materials with hexagonal periodic order of the mesopores. ${ }^{[43]}$ Here, they evidenced the presence of the pentasil subunit in the pore walls of the mesopores by IR spectroscopy. During the same year, Zhang et $a l{ }^{[44,45]}$ employed *BEA and ZSM-5 seeds in combination with CTAB and named the achieved material, obtained through hydrothermal treatment, SAM-5. The authors confirmed the presence of zeolite fragments in the pore walls of SAM-5 through Raman spectroscopy. Li et al. ${ }^{[46,47]}$ disclosed that optimized 
aging times of the zeolite $\mathrm{Y}$ seeding gel leads to materials with higher hydrothermal stability, acidity, and long range hexagonally structured mesoporosity.

The group of Pinnavaia further disclosed synthetic conditions that lead to the development of the cubic Ia3d mesophase by adding ethanol as co-solvent to the synthetic mixture that containing the surfactant CTAB and the FAU zeolite seeds formed from metakaolin. ${ }^{[48]}$ The use of the alcohol was previously disclosed for the synthesis of MCM-48 as it permits to efficiently augment the micelle packing parameter, which causes the denser micelle arrangement. ${ }^{[49]}$ The by this means achieved cubic mesoporous aluminosilicates featured zeolite fragments in their pore walls and was named Al-MSU-S 48 .

Approaches based on different paths other than S+I- where investigated employing protozeolitic species. The group of Pinnavaia extended this approach by combining zeolite seeds in acidic conditions with non-ionic surfactants. ${ }^{[50]}$ Hereto, the $\mathrm{pH}$ of the zeolite seeding solution was lowered below 7 before adding the neutral surfactant Pluronic $123\left((\mathrm{EO})_{20}(\mathrm{PO})_{70}(\mathrm{EO})_{20}\right)$ and trimethylbenzene (TMB) as micelle swelling agent and hydrothermally treating the mixture. The authors evidenced that the porous features of the obtained materials could be influenced by the $\mathrm{pH}$ of the synthesis solution. Indeed, when the $\mathrm{pH}$ was between 2.5 and 6 , a foam-like structure built up by strut-like walls which frame windows opened into spherical cells with narrow pore size distributions. The material was denominated MSU-S/F. When the $\mathrm{pH}$ of the synthesis solution was higher $(\mathrm{pH}=$ $6-7)$, MSU-S/H materials where obtained. These materials featured long range ordered hexagonal mesoporosity. Analogous to the previously described MSU-S materials, the MSU-S/F and MSU-S/H present zeolite fragments in their pore walls, as evidenced by IR spectroscopy.

The achievement of distinct mesophases as a function of the $\mathrm{pH}$ strongly suggests that the synthesis follows different mechanistic routs. Both syntheses were performed at $\mathrm{pH}$ above the isoelectric point of the zeolite precursor species, which indicates that in either case the inorganic species were negatively charged. Moreover, wormhole mesostructured aluminosilicates (Al-MSU-S $\mathrm{W}_{\mathrm{W}}$ ) were achieved by employing the non-ionic compound tallow tetraamine in slightly basic conditions in combination with $\mathrm{Y}$ zeolite seeds. ${ }^{[48]}$ In this case, the supramolecular assemblies formed through $\pi-\pi$ stacking. It is yet not evident to 
ascribe to which favorable interactions between the neutral amine and the negatively charged zeolite seeds the formation of the mesostructured material under the applied $\mathrm{pH}$ conditions may result. Indeed, in a more recent publication by the same group, the experimental section states acidic synthesis conditions for the formation of the Al-MSU-S $S_{\mathrm{W}}$ material employing tallow tetaamine. ${ }^{[51]}$ In such conditions, the formation mechanism can readily be described to follow a $\mathrm{N}^{0} \mathrm{H}^{+} \mathrm{I}^{-}$ interaction.

It is important to mention now, that the examples presented up to this point do not achieve truly hierarchical zeolites as they lack crystallinity and therefore cannot be described as zeolites. However, they have paved the way to fully crystalline hierarchical zeolites and are excellent examples of the versatility of surfactanttemplating for the achievement of various complex mesoporous architectures. In fact, the employment of zeolite seeds in combination with surfactants has further been reported to achieve truly hierarchical zeolites. Here, the critical key factors enabling the obtaining of crystalline mesopore walls are based on the nature of the zeolite seed (i.e. the condensation degree) and the nature of the surfactant head group (and the eventual use of co-solvents).

\subsubsection{Hierarchical zeolites through judicious choice of surfactant-templating} conditions employing seeds

Mesoporous zeolite assemblies were achieved by the self-assembly of zeolite FAU seeds with the cationic surfactant CTAB in the presence of co-solvents and micelle swelling agents during hydrothermal synthesis. ${ }^{[52]}$ The authors indicated that trimethylbenzene (TMB), used as swelling agent, and tert-butyl alcohol (TBA), employed as co-solvent, both work synergistically to produce the hierarchical zeolites. The authors argue the ability of the tertiary alcohol to reduce repulsive forces of the surfactant headgroups, leading thus to an increase in the micelle packing parameter and hence in the micelle charge density. Through this strategy the affinity between the micelles and the aluminosilicates species are enhanced. The authors further estimated that as TMB promotes the zeolite surfactant assembly by swelling the surfactant micelle allowing to match to the zeolite precursor species size.

Zhu et al. ${ }^{[53]}$ put forward that the achievement of hierarchical zeolites by using seeds is critically influenced by the polymerization degree of the nanometer sized 
species. The authors kinetically controlled the seed formation, which then in a second step, were subjected to hydrothermal treatment in combination with CTAB. Depending on the amount of surfactant and of co-solvent used in the synthesis, hierarchical ZSM-5 featuring disordered mesoporosity with narrow size distribution could be achieved (Figure 4).

A similar approach was developed through the combination of CTAB with pluronic F127 and ZSM-5 zeolite seeds. ${ }^{[54]}$ Here, the zeolite building units firstly aggregated with the CTAB micelles before assembling with the F127 (which concentration gradually augments during the temperature treatment by the evaporation of the solvent). The authors observed that the F123 micelles stacked along the $b$ direction of the crystals. Hence, a hierarchical ZSM-5 with a dual pore size distribution composed out of smaller CTAB-templated disordered mesopores and larger mesopores oriented along the b-axis of the ZSM-5 crystals were achieved.

Further, the nature of the polar headgroup was indicated to have a major influence in the efficient assembly of zeolite seeds. It was described that the imidazolium-based ionic liquid $\left[\mathrm{C}_{16} \mathrm{MIm}\right] \mathrm{Cl}$ when employed as surfactant in the hydrothermal treatment with MFI seeds, proved to be suitable for the achievement of hierarchical ZSM-5 with partially ordered mesoporosity. ${ }^{[55]}$ Indeed, it was previously indicated for the synthesis of MCM-41 that the imidazolium headgroup allows for a stronger binding strength to charged silica species and to a higher binding density. ${ }^{[56]}$ It is these features that critically influence the surfactant-templating ability.

Protozeolitic FAU and *BEA seeds have further been combined with the cationic polymer PDADMAC to achieve zeolites containing disordered mesopores. ${ }^{[56,57]}$ It remains yet questionable whether the reported zeolites truly contains mesoporosity, as the presented nitrogen physisorption experiments indicate type I isotherms and the narrow pore size distribution put forward by the authors should more correctly be ascribed to cavitation than to tailored mesoporosity. ${ }^{[59]}$ 
3.1.4 Hierarchical zeolites through the functionalization of seeds with organic functions

A devised approach was developed by the group of Serrano based on the functionalization of zeolite seeds and their subsequent crystallization. ${ }^{[60-62]}$ They developed protozeolitic units comprised between 2 and $5 \mathrm{~nm}$. These were subsequently silylated through standard grafting techniques employing phenylaminopropyltrimethoxysilane in order to achieve zeolite seeds functionalized with aromatic groups. Further, the functionalized seeds were subjected to hydrothermal conditions to promote zeolite crystallization (Figure 5). Hence, zeolites composed out of aggregates of small size developed. The authors assessed the role of the organic surface moieties to perturbate the zeolite crystallization leading to the formation of interparticular mesoporosity within the single aggregates. It was furthermore shown that the amount of formed mesoporosity was determined by the amount of grafting agent used in the synthesis. Diversely, the functionalization of zeolite seeds with hydrocarbon chains of different length revealed not very successful to develop hierarchical features and bulk zeolites were obtained. Based on the observation that solely the functionalization with phenyl groups allowed for the achievement of the intergrown zeolite structures, it could be put forward that $\pi$ - $\pi$ interactions between the functional moieties during the crystallization process play a crucial role in the assembly of the nanozeolites. Here, a so far unexplored approach can be put forward, which would represent the simultaneous use of surfactants comprising aromatic groups that could interact through $\pi-\pi$ interactions with the moieties on the surface of the functionalized seeds.

Although the assembly of nanosized zeolites with surfactants produced hierarchical zeolites, presenting zeolite X-ray diffraction peaks, it appears that this strategy leads to the formation of zeolite aggregates (Figure 5C). Indeed, such approaches have yet yielded individual zeolite crystals featuring intracrystalline mesoporosity.

\subsection{Hierarchical zeolite synthesis with silane-terminated quaternary amines:} linking the surfactant to the zeolite precursor

Ryoo and coworkers have greatly contributed to the development of surfactanttemplated hierarchical zeolites, through the design of a new family of surfactants 
based on amphiphilic silanes comprising a hydrophobic tail and a modified headgroup, which is covalently linked to a trialkoxysilane moiety. These surfactants enable to circumvent the typical drawbacks encountered with classical cationic amphiphiles in the synthesis of hierarchical zeolites, by presenting unique features: i) the ability to form covalent bonds with inorganic species by hydrolysis and condensation, ii) the capability of the ammonium head group to act as zeolite SDA and iii) the ability of the hydrophobic chains to efficiently form mesophases through self-assembly. These features together allow to achieve hierarchical zeolites by preventing phase separation into two distinct phases.

The first silylated surfactant that was described was 3-(trimethoxysilyl)propylhexadecyldimethylammonium chloride (TPHAC), ${ }^{[63]}$ that was directly added to the synthesis mixture of ZSM-5 and LTA prior to hydrothermal treatment. The achieved zeolite phases feature disordered, wormhole-like porosity with very narrow mesopore size distributions (Figure 6). They proved the surfactanttemplating ability of this new type of surfactant through the tunability of the mesoporous size distribution by varying the length of the hydrophobic chain between 12 and 18 carbon atoms. They furthermore proved that synthesis time and temperature crucially influences the size distribution of the mesoporosity. Additionally, the amount of the organosilane added during the synthesis is a critical parameter that influences the mesoporous size distribution and generated mesoporous volume. The intracrystalline nature of the mesophase was assessed by a combination of high resolution scanning electron microscopy (HR-SEM) with cross-sectioning through an argon beam. ${ }^{[64]}$ Further, the presence of disordered, interconnected wormhole-like mesoporosity was evidenced by visualizing the porous architecture through the formation of $\mathrm{Pt}$ nanowires within the zeolite crystals, which were subsequently imaged by TEM. ${ }^{[65]}$

The same group successfully employed this approach for the development of mesoporous sodalite, describing its first application as basic catalyst. ${ }^{[66]}$ TPHAC revealed moreover as a suitable surfactant for the achievement of the hierarchical zeotypes $\mathrm{ALPO}_{4}-5$ and ALPO-11 featuring in both cases tailored mesoporosity. ${ }^{[67]}$

Inayat et $a l .{ }^{[68]}$ were the first to employ the silylated surfactant TPHAC for the synthesis of FAU type zeolites displaying a unique hierarchical porous structure that is built up by zeolite nanosheets assembled in a house-of-cards like fashion, 
featuring macroporous interstices located within the nanosheet stacks. The distance between the individual nanosheets in this construction is of approximately $7 \mathrm{~nm}$ through which the zeolite macropores are accessible. Very recently, Qamar and co-workers reported the synthesis of nanocrystalline mesoporous $\mathrm{Y}$ zeolite featuring octahedral facets using again TPHAC as surfactant. ${ }^{[69]}$ The authors further evidenced that the amount of the employed surfactant represents a critical factor that controls the dimensions of the obtained nanocrystals.

TPHAC was furthermore used in combination with micelle expanding agents in the zeolite LTA synthesis. ${ }^{[65]}$ Triblock co-polymer P123 (EO20PO70EO20) was employed as swelling agent, which allowed to efficiently increase the mesopore size from 7.4 to $23.7 \mathrm{~nm}$. The authors assumed that the non-ionic surfactant permeates into the hydrophobic region formed by the TPHAC surfactant chains, which thus leads to an expansion of the micelles and hence to larger mesopores.

A novel surfactant based on amphiphilic silanes, developed by Han et al. ${ }^{[70]}$ and featuring a double-acyloxy with double $\mathrm{C}_{12}$ alkyl chains, 2,3bis(dodecanoyloxypropyl)-[3-(trimethoxysilyl)-propyl]dimethylammoniumiodide (BTDAI) was used to produce hierarchical ZSM-5. More precisely, the presence of BTDAI within the zeolite synthesis gel allowed for the achievement of hierarchical ZSM-5 zeolites with platelet-like morphology and a wide mesopore size distribution. Shortly thereafter, the authors studied the influence of varying both the chain length of the BTDAI-type surfactants and its concentration in the synthesis mixture. Under optimized conditions mesoporous volumes up to $0.19 \mathrm{~cm}^{3} \mathrm{~g}^{-1}$ were achieved. ${ }^{[71]}$

\subsection{Hierarchical zeolites by surfactants with multiple quaternary ammonium centers}

A major breakthrough in the surfactant-templating of zeolites was achieved by Ryoo and co- workers through the design of surfactants featuring various quaternary ammonium centers. In their pioneering publication, the group presented the achievement of MFI-type zeolites composed by nanosheets of a size of a single unit cell. ${ }^{[72]}$ In this way, ultrathin zeolite layers were produced that were three-dimensionally intergrown to form the hierarchical zeolite structure. The employed surfactant, namely $\mathrm{C}_{22-6-6}\left(\mathrm{C}_{22} \mathrm{H}_{45}-\mathrm{N}\left(\mathrm{CH}_{3}\right)_{2}-\mathrm{C}_{6} \mathrm{H}_{12}-\right.$ 
$\left.\mathrm{N}\left(\mathrm{CH}_{3}\right)_{2}-\mathrm{C}_{6} \mathrm{H}_{13} \mathrm{Br}_{2}\right)$, is composed of two quaternary ammonium centers spaced by $\mathrm{C}_{6}$ alkyl chains, that together form the structure directing group of the MFI phase whilst the long hydrocarbon tail $\left(\mathrm{C}_{22}\right)$ acts as mesostructuring template by forming supramolecular micellar assemblies via hydrophobic interactions. The secondary role of the hydrophobic chain is to restrict the growth of the zeolite, leading to sheets of thicknesses of a few pentasil units of $2 \mathrm{~nm}$ spaced by $2.8 \mathrm{~nm}$ thick micellar layers (Figure 7 top).

The same research group evidenced by low and wide angle XRD that the nanosheet assembly develops from an initial hexagonal organized mesophase with amorphous pore walls, which is subsequently transformed through heat treatment into a lamellar mesophase with walls that are built up by the crystalline zeolite framework (Figure 7 bottom). ${ }^{[73,74]}$

Very recently $\mathrm{Xi}$ et $a l .^{[75,76]}$ carried out computational simulations in order to describe the distribution of the LUMO (lowest unoccupied molecular orbital) on multiple quaternary ammonium centered surfactants. Through this study the authors were able to reason the role of the inner ammonium groups to direct the synthesis of the MFI phase.

An excellent example that highlights the importance to rationally design surfactants by taking into account their charge density and their structure was presented by the group of Ryoo, who developed tricationic surfactants composed out of two long alkyl chains of identical length and where the ammonium groups were spaced by $\mathrm{C}_{6}$ alkyl segments $\left(18-\mathrm{N}_{3}-18\right) .{ }^{[77]}$ This surfactant allowed for the achievement of an ordered mesoporous structure which presents broad peaks in the high angle XRD region of very low intensity, suggesting a regular stacking of lattice planes with atomic-scale ordering at least to some extent (Figure 8). Indeed, the determination of the crystalline framework structure is bounded and can rather be ascribe as "pseudocrystallinity". The flexibility of this approach was further pointed out by using surfactants with four ammonium groups spaced by $\mathrm{C}_{6}$ alkyl segments $\left(18-\mathrm{N}_{4}-18\right)$ and additionally feature aromatic groups as spacers; giving rise to the surfactants $\mathrm{N}_{4}$-phe, $\mathrm{N}_{6}$-diphe, and $\mathrm{N}_{8}$-triphe. The authors reported that through the increase of the amount of cationic centers in the surfactants the obtained mesostructure lost structural order. In the same direction, the wall thickness increased from 2.9 to $5.1 \mathrm{~nm}$ for the surfactants with four and eight cationic centers, respectively. 
Micron sized SSZ-13 zeolite (CHA structure) assembled to form mesoporous aggregates was achieved by $\mathrm{Wu}$ et $a l .{ }^{[78]}$ through the use the bi-quaternary surfactant $\mathrm{C}_{22} \mathrm{H}_{45}-\mathrm{N}\left(\mathrm{CH}_{3}\right)_{2}-\left(\mathrm{CH}_{2}\right)_{4}-\mathrm{N}\left(\mathrm{CH}_{3}\right)_{2}-\mathrm{C}_{4} \mathrm{H}_{9} \mathrm{Br}_{2}$ together with the zeolite SDA, N,N,N-trimethyl-1-adamantanammonium hydroxide (TMAdOH).

The group of Ryoo further developed a new surfactant composed out of three cationic centers bridged by $\mathrm{C}_{6}$ unities and ended symmetrically by two $\mathrm{C}_{18}$ tails. By the addition of this surfactant to the ZSM-5 synthesis gel, ultrathin MFI nanosheets of a single pore thickness of $1.5 \mathrm{~nm}$ were obtained, which represents less than a single crystal unit-cell dimension $(2.0 \mathrm{~nm}) .{ }^{[79]}$ Compared to the bulk zeolite, the obtained nanosheets present comparable acidity, thermal and hydrothermal stability. The examples presented up to now strongly indicated the necessity of at least two ammonium headgroups in the surfactant in order to reach hierarchical organized structures. ${ }^{[28]}$

This assumption was counterevidenced by the group of Che ${ }^{[80]}$ who designed surfactants featuring merely one cationic center able to produce the nanosheets, organized in such a way to form hierarchical assemblies. The authors firstly studied the role of CTAB in the synthesis of MFI type zeolites, which in the appropriate conditions acts as conventional short chain SDA of the MFI structure, in which the surfactant tails are located in the straight channels of the zeolite framework. ${ }^{[81]}$ The authors suggest that the sole interaction between the surfactant tails is not strong enough to prevent the zeolite crystallization to occur in the conventional way. Based on this evidence, surfactants were rationally designed by ending the surfactant tails with aromatic groups, which enables them to interact through $\pi$ - $\pi$ stacking (Figure 9). This allowed for the formation of ordered MFI nanosheets, spaced by the surfactant micelles in which center the aromatic groups were located. ${ }^{[82]}$ Furthermore, they prepared bolaform type surfactants that due their $\pi-\pi$ stacking ability proved suitable candidates for the preparation of single crystalline MFI nanosheets, which were assembled through a $90^{\circ}$ rotational intergrowth of the sheets. The authors further indicated that single and double-branched ammonium-based surfactants featuring aromatic groups were restricted to direct the synthesis to lamellar nanosheets of the MFI structure (Figure 9C). The same group rationalized a new family of surfactants which can be seen as triple branched surfactants where the three branches are connected to a common aromatic center and which branches contain multiple cationic 
ammonium groups. Through the use of this surfactant in the synthesis gel, a single crystalline mesoporous ZSM-5 could be achieved featuring intracrystalline slit-like mesoporous arrangements. ${ }^{[83]}$ The authors reasoned the achievement of this structural feature by dividing the role of the three branches of the surfactant. Whilst two of the surfactant branches align within the straight MFI microporous channels, the remaining branch directs the micropores along the zigzag channel. The aromatic centers of the surfactant assemble through $\pi$ - $\pi$ stacking leading to the development of tailored mesoporosity.

The up to now described approaches for the formation of hierarchical structures proved to be of great versatility. A considerable variety of surfactants have been developed up to the point of presenting an entire design concept for the development of mesoporous features (Figure 10). Yet, the synthesis of such functional surfactants is often complex and expensive. It is difficult to conceive any commercial application of hierarchical structures described by the above techniques. Furthermore, in most cases aggregation of nanosized zeolites and/or the development of intergrown nanosheets is observed. Indeed, these bottom-up surfactant-oriented approaches do not produce truly zeolite crystals that feature intracrystalline mesoporosity and at the same time intense zeolite crystallinity. Nonetheless, these developed strategies have greatly contributed to the comprehension of the interaction of surfactants during zeolite growth.

\section{Surfactant-templating strategies through post-synthetic treatment of zeolites}

Post-synthetic treatment of zeolites in the presence of surfactants has revealed as a powerful and convenient approach for the development of hierarchical porosity. Two main approaches can be distinguished within the post-synthetic strategies that yield markedly different materials. Hence, a careful consideration of both approaches is critically important. These two strategies have been coined with the terms "zeolite recrystallization" and "zeolite surfactant-templating". Occasionally, these strategies are mistaken in the literature. ${ }^{[84]}$ The fundamental difference between the strategies is that whilst in recrystallization the zeolite is exposed to severe basic conditions prior to the addition of the surfactant, in zeolite surfactant-templating the zeolite is treated with a milder basic solution that contain the surfactant (Figure 11). 


\subsection{Zeolite recrystallization in the presence of surfactants: A dissolution and precipitation process}

Goto et $a l .{ }^{[85]}$ were the first to describe materials achieved through the postsynthetic treatment of various zeolites in basic conditions followed by the addition of surfactants and thermal processing. The authors reported the treatment of zeolites with solutions of different basicities (from 0.75 to $3 \mathrm{M}$ of aqueous $\mathrm{NaOH})$ for a fixed time interval $(30 \mathrm{~min})$ prior to the addition of the surfactant (CTAB) and hydrothermal treatment at $150{ }^{\circ} \mathrm{C}$ with intermediate $\mathrm{pH}$ adjustment to 8.5. Composite materials consisting of a purely mesoporous yet amorphous phase and of the parent zeolite were obtained. The amount of the mesoporous amorphous phase revealed to be dependent on the concentration of the base, as the dissolution of the zeolite was favored at increased $\mathrm{pH}$ (Figure 12). The authors found striking similarities in the obtained composite materials when MOR and ZSM-5 were used, yet the employment of Al rich zeolites, i.e. zeolites with low $\mathrm{Si} / \mathrm{Al}$ ratios (such as $\mathrm{Y}$ and LTA) reveled as unfruitful. Most likely, the high $\mathrm{Al}$ content of the zeolite hinders the process. It is important to stress, that whilst the information gathered from nitrogen physisorption and from the XRD does not allow to distinguish between the presence of a truly hierarchical zeolite and a composite material, the SEM images clearly indicate the presence of two phases for the materials prepared by Goto et al. (Figure 12). The described example illustrates the importance to characterize the materials through complementary techniques that together allow to discriminate between truly hierarchical solids and composites.

Ivanova and co-workers eventually coined the terms "zeolite recrystallization" to refer to this process. ${ }^{[86]}$ Yet, this denotation is somewhat deceptive as actually a noncrystalline phase is produced as a result of the treatment and therefore there is no real recrystallization. It appears more adequate to refer to a dissolution and re-assembly process. As a function of the severity of the dissolution step, the authors divided the achieved composites into three distinct materials classes (Figure 11) ${ }^{[87,88]}$ The RZEO-1 materials (also described as RMI) are obtained through the treatment of zeolites with mild basic conditions (generally below $1 \mathrm{M}$ ) and can be described as partially desilicated zeolite covered by a thin layer of amorphous mesoporous material. Through applying more sever basic conditions; composite materials described as RZEO-2 were achieved. RZEO-3 materials (also named RMII) are achieved through more severe basic 
treatments (basic concentrations above $1 \mathrm{M}$ ) and can be described as purely amorphous mesoporous aluminosilicates that contain zeolite fragments within the pore walls. It is important to mention that a $\mathrm{pH}$ readjustment is required for synthesis where the $\mathrm{pH}$ exceeds 12 , through the intermediate addition of acid to lower $\mathrm{pH}$ values in the range of 8 and 10.5 to allow the precipitation of the amorphous phase in the presence of the surfactant. The RZEO materials where extensively studied by ex situ MAS NMR and IR. Based on the observations on H-MOR zeolite, Ivanova et al. ${ }^{[89]}$ proposed the following mechanism to account for the formation of the RZEO-1, 2 and 3 materials:

1) As result of the exposure of the zeolite to the basic solution $(\mathrm{NaOH})$, fast ion exchange between the sodium cations with the zeolite protons and destruction of the silicon-oxygen bonds through alkali are observed, leading to desilication and the formation of large mesopores (3-20 nm) within the crystal and even wider pores in between the crystals.

2) Owing to the addition of $\mathrm{CTAB}$, the diffusion of surfactant molecules within the inter- and intracrystalline space takes place, leading to ion exchange of the sodium cations with $\mathrm{CTA}^{+}$. The surfactants then form micelles inside the in step 1) developed cavities.

3) The mesophase finally forms through the condensation of the inorganic species dissolved from the zeolite framework in step 1) around the surfactant micelles.

Though the RZEO-3 were described as purely amorphous ordered aluminosilicates featuring no zeolite crystallinity, spectroscopic techniques allowed for evidencing the presence of zeolite subunits within the pore walls that built up the mesoporous structure. The authors ascribed to the presence of these zeolitic fragments within the walls superior hydrothermal stability and enhanced catalytic properties of these materials over Al-MCM-41. ${ }^{[88,90]}$

Boukoussa et al. ${ }^{[91]}$ further described the influence of the amount of employed CTAB on the textural characteristics of the composite materials by using ZSM-5 as starting zeolite. Similar conclusions were drawn by Liu et al. ${ }^{[92]}$ using ZSM22. $\mathrm{Na}$ et al. ${ }^{[93]}$ reported the control of the pore size as a function of the chain length of the employed trimethylalkylammonium-based surfactant. The synthesis rout was further applied to TS-1, leading to titanosilicates with mesoporosity of a wider size distribution. ${ }^{[94]}$ 
Solely one article reports the employment of other than trimethylalkylammonium-based surfactants in the zeolite recrystallization process. ${ }^{[95]}$ Here, mesoporous titanosilicates were achieved by employing the unsymmetrical Gemini surfactant $\mathrm{C}_{18} \mathrm{H}_{37} \mathrm{Me}_{2} \mathrm{~N}\left(\mathrm{CH}_{2}\right)_{6} \mathrm{NPr}_{3} \mathrm{Br}_{2}$. A core/shell titanosilicate consisting of a highly crystallized MFI (TS-1) structure both in the core and in the shell yet featuring different framework unit cell long-range extensions was produced (Figure 13).

\subsection{Zeolite mesostructuring through post-synthetic zeolite surfactant-templating}

A post-synthetic surfactant-based strategy allowing for the introduction of mesoporosity within zeolite crystals was firstly reported by Garcia Martinez et al., ${ }^{[96]}$ and later described as mesostructuring to emphasize the precise control over the mesopore size and organization ascribable to the use of surfactants. ${ }^{[97]}$ This post-synthetic strategy differs substantially from the previously described recrystallization process as it permits for the development of intracrystalline mesoporosity within a wide number of zeolites comprising the FAU, MFI, CHA, *BEA and MOR structures, among others. ${ }^{[96]}$ The mesostructuring process is rather simple and relies on the treatment of a parent zeolite with cationic surfactants in basic $\mathrm{pH}$ conditions.

Through comparing the TEM micrographs of the parent and the mesostructured zeolite, the introduction of tailored mesoporosity distributed homogenously throughout the entire crystal becomes evident (Figure 14D and E). This was further proved from the FE-SEM micrographs, which show smooth crystal surface for the parent zeolite whilst the mesostructured zeolite presents abundant mesoporosity (Figure 14B and C). Moreover, the crystal morphology of the original zeolite is maintained after the mesostructuring process; it is for this reason that this treatment has been described as pseudomorphic transformation. ${ }^{[98]}$

A strong evidence of the surfactant-templating effect was obtained through the use of surfactants with increasing aliphatic chain lengths (Figure 14F and G). From argon physisorption experiments, an excellent linear correlation between the number of carbon atoms in the surfactant and the achieved mesopores diameter was observed; tailorable in the range from 3.0 to $5.5 \mathrm{~nm} .^{\text {[99] }}$ 
Very recently, the development of tailored mesoporosity was observed through in situ XRD synchrotron radiation (Figure 14G). ${ }^{[100]}$ This study revealed the gradual evolution of two peaks in the low angle range of the diffractogram corresponding to the formation of the mesoporosity within the zeolite by the surfactant CTAB. These peaks were interpreted through theoretical calculations, revealing the development of short-range ordered mesoporosity. Indeed, through progressively decreasing the size of a zeolite crystal containing hexagonally ordered mesopores, the merging of the corresponding (11) and (20) planes in the simulated diffractograms was observed (Figure 14H). It can hence be assumed that the features in the low angle XRD range that develop during surfactant-templating can readily be ascribed to a local hexagonal order of the forming mesoporosity. The theoretical calculations further evidenced a slight decrease of the intensity of the XRD peaks due to a less efficient diffraction caused by the introduction of intracrystalline mesoporosity. This is in agreement to what has been observed experimentally. Furthermore by analyzing the intensity and the FWHM of the XRD peaks it could be evidenced that the mesoporous zeolites present a larger coherent crystal size, which consists of small lattice domains aligned to form part of a single crystal.

It is important to note that an in situ XRD experiment preformed in the absence of CTAB shows a very fast decrease of intensity of the zeolite phase (and falls to zero within 10 min of the experiment) whilst no additional peaks could be distinguished in the low angle region. This result hence highlights the striking difference between desilication and zeolite surfactant templating.

Liquid-Cell Transmission Electron Microscopy (Liq-TEM) has developed to a powerful tool for the in situ characterization of processes in materials chemistry. ${ }^{[101]}$ Liq-TEM was used for the first time in the direct visualization of the changes in the morphology of individual zeolite crystals during surfactant-templating. ${ }^{[100]}$ The progressive reconstruction of the zeolite crystals could be evidenced by the time-resolved imaging of larger mesopores (due to steaming) present in the parent zeolite (Figure 14I).

These evidences strongly suggest that the development of intracrystalline mesoporosity produces the rearrangement of the zeolite structure (Figure

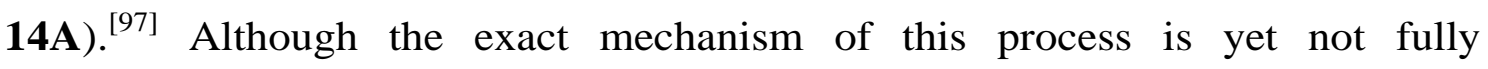
understood, it has been suggested that the first stage of the transformation is related with the fast uptake of the cationic surfactant by the zeolite at basic $\mathrm{pH}$. The base reacts with some of Si-O-Si bonds allowing for the fragilization of the 
structure that rearranges in order to accommodate the forming surfactant micelles within the structure.

The proposed mechanism does not involve the dissolution and recrystallization of the zeolite species, as misrepresented in some publications, ${ }^{[84,102]}$ but the shortscale rearrangement of the zeolite framework to accommodate the developing surfactant-micelles. Consequently, the zeolite crystals expand throughout the process as was inferred by measuring crystal sizes from electron microscopy micrographs. ${ }^{[103]}$

The occurrence of desilication or dealumination could be unambiguously discarded through the careful analysis of the filtrates throughout the process and by observing constancy of the Si/Al ratio and of the unit cell size (UCS) of the zeolites during the process. Further, recovery yields of calcined mesostructured zeolites approximate to $100 \%$. This is a further evidence that the employment of the surfactant during the basic treatment prevents any significant dissolution of the zeolite and leads to the mesostructuration. Moreover, it was observed that the employment of small tetraalkylammonium cations (such as tetrapropylammonium hydroxide) preserve the zeolite crystallinity during base treatment, indicating the ability of such cations to preserve from zeolite desilication. ${ }^{[104]}$ Yet, in these cases no tailored mesoporosity develops due to the inability of these cations to form micelles and hence no surfactant-templating is observed.

As previously betoken, zeolite phases featuring low $\mathrm{Si} / \mathrm{Al}$ ratios (i.e. $\mathrm{Si} / \mathrm{Al}<3$ ) are not prone to react in basic conditions as a result of the stability of the Si-O-Al bonds at high $\mathrm{pH}$. To overcome this limitation, Garcia Martinez and co-workers proposed a mild acid pre-treatment, which allows to selectively open some of the Al-O-Si bonds yet without significantly dealuminating the zeolite. ${ }^{[105]}$ Merely a slight reduction of the UCS of the framework and a small increase in the Si/Al ratio indicated limited removal of $\mathrm{Al}$ species from the zeolite structure. For example, the acid treatment applied to a $\mathrm{Na}-\mathrm{Y}$ zeolite with $\mathrm{Si} / \mathrm{Al}=2.5$, results in the increase to the same ratio to 3.5 . This ratio is significantly lower than the elevated $\mathrm{Si} / \mathrm{Al}$ ratios required by USY and other zeolites (typically $\mathrm{Si} / \mathrm{Al}>15$ ) for the formation of mesoporosity. Yet, the subsequent surfactant-templating of the acid-treated $\mathrm{Na}-\mathrm{Y}$ zeolite in the presence of both, the base and CTAB, allows for the introduction of tailored mesoporosity within aluminum-rich zeolites. 
Due to the efficiency that surfactant-templating presents for the introduction of tailored mesoporosity within zeolites, Galarneau et al. ${ }^{[106]}$ employed mesostructured zeolites as model structures for assessing the validity of the $t$-plot method. The authors reported that the classically employed $t$-plot approach considerably underestimates microporous volume in hierarchical materials. Based on their observations an abacus for correcting the values obtained from the $t$-plot method was proposed. Ascribable to their well-defined structure, mesoporous zeolites obtained by surfactant-templating can be seen as unique model materials since the size and amount of introduced mesoporosity can readily be tailored. This anticipates their future use as reference materials in a wide variety of fields.

Sachse et al. ${ }^{[107]}$ recently employed new surfactants relying on imidazolium and pyridinium based ionic liquids, in the zeolite surfactant-templating process. The authors observed that despite the fact that all of the surfactants present similar templating ability for the formation of ordered mesoporous silica, their employment in zeolite surfactant-templating allows for the achievement of different porous features. Based on this observation the authors suggest that micellization occurs differently in the confined zeolite spaces. These findings are a further proof that fosters the rearrangement mechanism. ${ }^{[97]}$

\section{Key characteristics of mesostructured zeolites required for industrial applications}

The development of mesoporosity in zeolites is driven by the quest for overcoming their diffusion limitations in many industrially relevant catalytic processes. In order to understand to which extent the main zeolite properties are affected upon introducing mesoporosity the in-depth characterization of various key features is essential; these are: $(i)$ the textural properties of the mesoporous zeolites, including the pore size and porous architecture, (ii) the crystallinity, (iii) the density, strength and nature of the acid sites and (iv) the hydrothermal stability. The assessment of these key properties is critically important to assert the suitability of mesoporous zeolites for large scale applications. In order to diligently describe these key features a variety of advanced characterization techniques are being developed and are becoming available. Some of the latest evolutions in this field have recently been reviewed by Perez-Ramirez and coworkers. ${ }^{[108]}$ 


\subsection{Textural and diffusional properties}

The full textural characterization of hierarchical zeolites comprises a detailed quantitative and qualitative appreciation of their porous architecture and porous interconnectivity at different length scales. The by far most widespread characterization technique for analyzing the porosity of hierarchical zeolites is nitrogen physisorption. Yet, nitrogen features a quadrupole moment, which implies that its molecular orientation strongly depends on the surface chemistry of the adsorbent. This leads to the major inconvenience of high uncertainty of its molecular cross-sectional area. Moreover, the presence of the quadrupole moment strongly affects the micropore filling pressure, which in some cases renders the measurement of equilibrated adsorption isotherms difficult. Additionally, the nitrogen molecule can hinder the pore entrances of small micropores through pre-adsorption, which makes the estimation of the micropore size distribution difficult. ${ }^{[109]}$ In this respect, argon physisorption techniques present important advantages. Argon features a smaller kinetic diameter and no quadrupole moment, weaker fluid-wall interactions and a higher adsorption temperature compared to nitrogen. These characteristics reduce diffusion limitations and allow for observing the micropore filling at higher relative pressures compared to nitrogen for zeolites. ${ }^{[110]}$

Moreover, measuring $\mathrm{Ar}$ isotherms at lower temperatures than its boiling temperature (e.g. 77 or $65 \mathrm{~K}$ ) allows to gain structural insights in the porous features of mesoporous zeolites. Recording Ar isotherms at such low temperatures influences the thermodynamic state of the confined fluid and allows for the observation of hysteresis even for very small mesopores (below $4 \mathrm{~nm}$ ). This is of crucial importance for mesoporous zeolites that feature small mesopores, where nitrogen physisorption reveals a reversible capillary condensation step. In a recent paper, Ar isotherms were recorded at 77 and $65 \mathrm{~K}$ for surfactant-templated USY zeolite. A combination of $\mathrm{H} 1$ and $\mathrm{H} 2$ hysteresis was observed, indicating that the majority of the mesopores are freely accessible without constriction ( $\mathrm{H} 1$ loop). The part of the hysteresis related to the $\mathrm{H} 2$ loop is due to mesopores accessible through the narrow microporous channels, i.e. mesopores imbedded in the zeolite crystal; which leads to the cavitation phenomena (Figure 15). ${ }^{[11]}$ A confirmation of this observation was gathered by 
analysis of hysteresis scanning measurements, where the pore system was partially filled up to defined partial pressures. By preforming several cycles through adsorbing various amounts of adsorbate, the presence of cavitation was unambiguously assessed as the scanning curves returned directly to the desorption boundary curve. The combination of these two techniques allowed for quantifying the amount of accessible and constricted mesoporosity in the mesostructured USY zeolites and amounted to 64 and $36 \%$, respectively for the material presenting a total mesoporous volume of $0.23 \mathrm{~cm}^{3} \mathrm{~g}^{-1}$. It has been argued that the presence of the constricted mesoporosity accounts as proof of the rearrangement process in which the diffusion of individual surfactant molecules within the microporous network and their subsequent self-assembly lead to the formation of mesoporosity within the zeolite crystals. It is important to mention, that longer surfactant-templating treatment times, yield materials which isotherms do not present the $\mathrm{H} 2$ loop, indicating that if enough time is allowed for the mesopore formation to occur all of the mesopores are accessible from the exterior of the crystal.

Microscopy techniques are undoubtedly one of the major tools allowing for the study of porosity at different length scales. Novel visualization techniques become ever more available for the detailed description of the porous features in hierarchical zeolites. One example hereof is electron tomography, allowing for the study of mesopore connectivity in zeolites. ${ }^{[112]}$ For deeper insights to these techniques the reader is oriented to consult the excellent review by Wei at al. ${ }^{[113]}$ that summarizes the existing visualization methods with special focus on the determination on the interconnectivity between the porosities.

The unique hierarchical and intracrystalline nature of the mesopores in surfactanttemplated zeolites was recently visualized though the combination of electron diffraction and microscopy studies by employing two advanced characterization techniques, i.e. electron tomography (ET) and rotation electron diffraction (RED). ${ }^{[14]}$ The combination of these techniques features the paramount advantage of overcoming the limitations of electron tomography (which does not permit for resolving the zeolite microporosity), as the RED method provides 3D structural information at the atomic level. ${ }^{[15]}$ Hence, the combination of these two techniques allowed for the unprecedented description and direct visualization of the porous architecture of the hierarchical zeolite from the atomic to the mesoscale (Figure 16). This allowed for the 
illustration of the porous architecture and of the mesoporous connectivity through the reconstructed model. ${ }^{[116]}$ The development of this technique has indeed been described as major advancement for the characterization of hierarchical crystalline solids. ${ }^{[117]}$ Here it allowed to unambiguously proof the crystallinity of the mesoporous zeolites and to discard the presence of any mesoporous amorphous material in the surfactant-templated material.

In addition to the textural characterization of hierarchical zeolites, the assessment of the impact of the porosity on the diffusion properties of the materials is of paramount importance. Galarneau et al. ${ }^{[118]}$ recently reported the study of masstransfer properties of post-synthetic surfactant-templated USY zeolite by pulsed field gradient nuclear magnetic resonance (PFG NMR). The authors compared the transport phenomena in USY zeolite, in surfactant-templated USY and in a mechanical mixtures of USY zeolite and Al-MCM-41 (Figure 17). Diffusion in the mechanical mixture could be described as a superimposition of the transport properties of the microporous zeolite and mesoporous solid. Differently, the effective diffusivity obtained for the surfactant-templated zeolite proved to be intermediate between that for the zeolite and the one observed for the mesoporous material and inferior to the one achieved in the mechanical mixture. This set of data not only proves the interconnectivity of the micro- (zeolitic) and mesoporosity (surfactant-templated) in one single phase but further that the hierarchical structure is effective in improving the diffusion properties of greatly hampered microporous solids. In addition, these results discard the formation of composite materials (mechanical mixture) through surfactant-templating as previously suggested. ${ }^{[84,102]}$

\subsection{Acidity}

The employed strategy for the formation of mesoporosity within the zeolites can have an important impact on the acid sites as their electronic environment may vary compared to the sites in the bulk zeolite. This is typically observed for hierarchical zeolites that are prepared through destructive techniques such as desilication. ${ }^{[19]}$ These strategies affect greatly the Si/Al ratio and further lead to defects in the structure as well as to partial amorphization of the material. This results in a substantial increase of Lewis acidity to the expense of Brønsted acidity and alters thus the acid characteristics of the parent zeolites. ${ }^{[120]}$ 
The post-synthetic surfactant-templating process does not present this inconvenient due to the employment of mild basic conditions and the protective role of the surfactant, allowing to maintain the acidic properties of the zeolites in a very unique manner while introducing a significant amount of mesoporosity. ${ }^{[97]}$ Various techniques have been developed to quantitatively and qualitatively assess the acidity of hierarchical zeolites, which are generally based on the adsorption of probe molecules. One of the most widely employed methods to determine the total acidity of zeolites is temperature programmed desorption of ammonia (TPD$\mathrm{NH}_{3}$ ). Yet, this method has been argued of not being accurate, as in many cases, adsorption on non-acid sites and re-adsorption of the probe molecule during the temperature treatment can readily occur, which makes it difficult to compare TPD-NH${ }_{3}$ profiles of bulk and hierarchical zeolites. ${ }^{[121]}$ Despite, Chal et al. compared the TPD- $\mathrm{NH}_{3}$ profiles of USY zeolite and of mesostructured USY through surfactant-templating, finding very similar global acidity in both samples (Figure 18A). ${ }^{[98]}$

A more comprehensive assessment of the acidity in zeolites is given through infrared spectroscopy. ${ }^{[122]}$ Indeed, through identifying characteristic vibrational bands it is possible to follow the development of silanol groups during the surfactant-templating process (Figure 18B). ${ }^{[97]}$ In pristine $\mathrm{NH}_{4}-\mathrm{Y}$ zeolite, two bands at 3640 and $3740 \mathrm{~cm}^{-1}$ are observed, characteristic for the vibrational frequencies of strong Brønsted acid $\mathrm{Si}-(\mathrm{OH})-\mathrm{Al}$ bonds and silanol $\mathrm{Si}-\mathrm{OH}$ bonds, respectively. After the acid treatment, the band centered at $3740 \mathrm{~cm}^{-1}$ increases substantially whereas the band at $3640 \mathrm{~cm}^{-1}$ decreases. This observation indicates the formation of new terminal silanol groups (sometimes also referred as hydroxyl nest) confirming the partial opening of the Si-O-Al bonds. Upon surfactant-templating, the $3640 \mathrm{~cm}^{-1}$ band significantly decreases which can be explained through the exchange of protons by $\mathrm{CTA}^{+}$and $\mathrm{Na}^{+}$. Through surfactant removal and exchange with $\mathrm{NH}_{4}{ }^{+}$, Brønsted acidity is then recovered. The selective opening of the Si-O-Al bonds was also proved through ${ }^{27}$ Al MAS NMR (Figure 18C). Here, the sole observation of tetrahedral Al indicates the absence of the formation of extraframework $\mathrm{Al}$ species throughout the entire process. ${ }^{\text {[97] }}$ One of the most suited techniques for the quantitative analysis of acid sites in zeolites is pyridine titration through the assignment of modes of the pyridine ions formed at Brønsted acid sites $\left(1544 \mathrm{~cm}^{-1}\right)$ and coordination complexes formed at 
Lewis acid sites $\left(1455 \mathrm{~cm}^{-1}\right)$. This technique was used to analyze the impact of the introduction of mesoporosity through surfactant-templating on USY zeolite. The pyridine adsorption followed by infrared spectroscopy indicated the presence of Brønsted and Lewis acidity for both, parent USY and surfactant-templated USY. It is quite remarkable that the introduction of a large amount of mesoporosity $\left(0.41 \mathrm{~cm}^{3} \mathrm{~g}^{-1}\right)$ within USY zeolite almost did not affect the acidic properties of the zeolite. Whilst the concentration of Brønsted sites diminished slightly for desorption temperature at $150^{\circ} \mathrm{C}$ (from 0.28 to $0.23 \mathrm{mmol} \mathrm{g}^{-1}$ ), the concentration of Lewis acid sites remained constant $\left(0.08 \mathrm{mmol} \mathrm{\textrm {g } ^ { - 1 }}\right)$. At desorption temperatures of $350{ }^{\circ} \mathrm{C}$ equal concentration of Lewis and Brønsted acid sites within both materials were determined (0.06 and $\left.0.15 \mathrm{mmol} \mathrm{g}^{-1}\right)$, indicating that the strongest acid sites remain unaffected through surfactanttemplating (Figure 18D).

\subsection{Hydrothermal stability}

Hydrothermal stability is an important key characteristic especially relevant for industrial applications, as the presence of steam at elevated temperature is common in industrial processes. The rapid loss of structural integrity is indeed one of the major drawbacks surfactant-templated silica-aluminas (such as AlMCM-41) present, making their industrial application impractical. ${ }^{[123]}$ Corma stated in his introductory 1997 review: "A strong improvement in stability could be obtained if one could make the walls crystalline. If this could be achieved one can dream of producing materials not only more stable and with stronger acidities than the current MCM-41 but also having in the same structure a combination of well-defined micro- and mesopores." In this respect, the development of intracrystalline mesoporosity within zeolites through surfactant-templating represents the achievement of this long lasting goal and allows the bridging of the gap between MCM-41 and zeolites. ${ }^{[103]}$

In order to assess the hydrothermal stability of mesostructured USY zeolite, its texture and crystallinity were compared before and after deactivation by steaming. To this purpose, their nitrogen isotherms and the X-ray diffractograms were compared at different steps during the preparation and after the deactivation (Figure 19). The nitrogen isotherm of the mesostructured $\mathrm{Y}$ zeolite featured a typical sharp nitrogen uptake at a relative pressure of approximately 0.5 as a result of the filling of surfactant- 
templated mesoporosity. Through the additional ultrastabilization process - that converts the mesostructured Y zeolite in mesostructured USY zeolite - the mesopores size became wider. Yet, the total mesoporosity remained almost constant. The deactivation of mesostructured USY zeolite simulating the process occurring in a FCC unit was achieved through treating the mesostructured USY at $788^{\circ} \mathrm{C}$ in pure steam for $4 \mathrm{~h}$. Though the mesoporous size distribution became wider throughout the treatment, its mesoporous volume kept constant, confirming excellent hydrothermal stability of the mesostructured zeolite. ${ }^{[97]}$

In the next section we will describe the impact of the mesostructured Y zeolite in fluid catalytic cracking (FCC). Proceeding to this, we would like to highlight that the excellent hydrothermal stability of the mesostructured zeolite was confirmed in month-long commercial FCC trials in a North American refinery. ${ }^{[124]}$ Hereto, the evolution of the zeolite surface area (ZSA, calculated through the $t$-plot method) and the mesoporous surface area (MSA, also called matrix surface area in industry; as the matrix accounts for a significant fraction of the mesopore surface area of the FCC catalyst it is calculated by subtracting the ZSA from the BET area) was monitored throughout the trial through periodic sampling of the equilibrium catalyst (Figure 19C). It was inferred that the ZSA of the equilibrium catalyst increased from 115 to $123 \mathrm{~m}^{2} \mathrm{~g}^{-1}(+7 \%)$, as a result of slightly higher ZSA in the fresh surfactant-templated zeolite. At the same time, an important increase in the MSA of the equilibrium catalysts, from $30 \mathrm{~m}^{2} \mathrm{~g}^{-1}$ before the trial to $50 \mathrm{~m}^{2} \mathrm{~g}^{-1}(+70 \%)$ towards the end of the trial was observed. The chemical analysis of the equilibrium catalysts further revealed the presence of $1000 \mathrm{ppm}$ of vanadium and $200 \mathrm{ppm}$ of nickel in the equilibrium catalysts. The presence of vanadium is known to harm FCC catalysts through the formation of vanadic acid, which forms through hydrothermal conditions present in the FCC unit. Notwithstanding, it was evidenced that the activity of the catalyst remained constant as to before of the trial through Micro Activity Tests (MAT). The excellent hydrothermal stability of the surfactant-templated USY, confirmed both in the lab and in the refinery, is an additional evidence of the presence of intracrystalline mesoporosity and discard the suggested amorphous nature of the mesoporous phase, as this would not stand the severe hydrothermal conditions applied. 


\section{Mesoporous zeolites in fluid catalytic cracking (FCC) and refining applications}

Zeolites play a central role in the petrochemical industry, being the main component of catalysts used in the processing of hydrocarbons through cracking, hydrocracking, isomerization and aromatization reactions, among many others. Especially the big five zeolite family (which comprises the phases Y, ZSM-5, FER, MOR and *BEA) presents unique properties such as strong Brønsted acidity, large surface area and hydrothermal stability, rendering them especially prone for these applications.

Activity, selectivity and deactivation are the key parameters that determine the efficiency of a catalytic process. All of them are crucially influenced by the masstransfer properties of the zeolite. A variety of catalytic test reactions have been established with the aim to assess the role of the secondary porosity in hierarchical zeolites. Many of the established test reactions are of industrial interest and comprise both the transformation of hydrocarbons and the production of chemicals, such as the methanol to olefins reaction and the Friedel-Crafts alkylation, just to cite a few examples. Hartmann et al. ${ }^{[125]}$ recently reviewed frequently employed test reactions that allow to determine the effect of secondary porosity in zeolites on their catalytic efficiency. Commonly, the employment of hierarchical zeolites affects the catalytic properties by $(i)$ improving conversion of bulky molecules, (ii) enhancing selectivity by avoiding secondary reactions (as a result of shorter diffusion path length) and (iii) reducing catalyst deactivation.

The role of intracrystalline mesoporosity on the catalytic activity and selectivity of hierarchical zeolites will here be exemplified through the application surfactant-templated USY in catalytic cracking. This represents the first example of an industrial application of a hierarchical zeolite moreover in a very demanding and important process such as fluid catalytic cracking (FCC). ${ }^{[99]}$

FCC is a key process in the petroleum refinery industry, which allows for transforming the high boiling point high molecular weight hydrocarbons present in the crude oil into lighter and more valuable fractions such as diesel, gasoline and olefinic gases. For a thorough introduction to FCC the reader is referred to the specialized literature. ${ }^{[126,127]}$

The main component of the FCC catalyst is zeolite $\mathrm{Y}$ as it is responsible for most of the catalytic cracking due to its unique structure, featuring 3D interconnected micropores, and to its strong acidity. Yet, a significant fraction of the reactant 
molecules in the feedstock are of larger size than the microporous channels of this zeolite. ${ }^{[128]}$ Consequently, mass-transfer is importantly hampered as solely the active sites located on the external surface of the zeolite crystals are able to transform the bulky molecules. The effect of diffusion limitations on the product distribution in FCC is schematically depicted in the simplified tree-lump model (Figure 20A). Under such conditions less vacuum gas oil (VGO) is converted into gasoline and light cycle oil (LCO) due to the accessibility issues. At the same time, as a result of the long diffusion path lengths in the bulk zeolites, secondary reactions occur (overcracking), which increases the selectivity towards undesired gases and coke.

To overcome this scenario, an important amount of work has been carried out with the aim to reduce the diffusion path length and to increase the number of accessible active sites in zeolites. It has indeed been reported that through employing nanosized zeolites, the selectivity towards reaction intermediates (i.e. gasoline and LCO) was increased whilst reducing the production of gases and coke. ${ }^{[129]}$ The achieved selectivity can be explained by taking into account the reduced diffusion path length in the nanosized zeolites, as the reaction intermediates, i.e. gasoline and LCO, reside less time within the crystalline structure and are thus less prone to undergo secondary reactions (i.e. overcracking) to form undesired gases and coke which deactivates the catalyst. $^{[130]}$

Despite the increased selectivity towards the gasoline fraction in FCC for which nanocrystalline $\mathrm{Y}$ zeolite accounts, several important drawbacks render their industrial application difficult. These are based on the low yield of the nanocrystals and their rather complex separation after synthesis. Additionally, such nanocrystals present lower hydrothermal stability than the bulk zeolites. ${ }^{[130]}$ A practical alternative for reducing the diffusion path length and at the same time maximizing the accessibility of active sites - and which does not present the afore mentioned drawbacks - is the introduction of mesoporosity within zeolite $\mathrm{Y}$. As previously described, mesoporous zeolite $\mathrm{Y}$ obtained through post-synthetic surfactant-templating presents excellent acidity and hydrothermal stability and at the same time tailored and interconnected mesoporosity. These features endow the mesostructured Y zeolite as ideal component of the FCC catalyst. 
For this purpose, the FCC catalyst was produced employing commercial techniques and tools at a pilot plant. ${ }^{[99]}$ Bulk $\mathrm{NH}_{4}-\mathrm{Y}$ zeolite was treated with a diluted citric acid solution in order to selectively open some of the Si-O-Al bonds. The sample was subsequently surfactant-templated to introduce tailored mesoporosity. The in this way achieved mesostructured $\mathrm{Y}$ zeolite was ultrastabilized by exposing it to $550{ }^{\circ} \mathrm{C}$ during $2 \mathrm{~h}$ in $100 \%$ steam. In order to further improve its hydrothermal stability, the mesostructured USY zeolite was rare earth ion exchanged. Finally, it was combined with clay (kaoline) acting as filler and a binder (aluminium chlorohydrol) and shaped into the FCC catalyst through spray drying. In order to simulate the equilibrium catalyst (Ecat), the achieved catalyst was deactivated through fluidized steaming at $788^{\circ} \mathrm{C}$ during $8 \mathrm{~h}$ in $100 \%$ steam. $^{[124]}$

The catalytic performance of the FCC catalyst containing the mesostructured zeolite $\mathrm{Y}$ was compared to a system prepared in identical manner but comprising the original $\mathrm{Y}$ zeolite. The FCC tests were carried out in an advanced cracking evaluation (ACE) unit using both light and heavy VGO as feedstock. In both cases, higher yields in gasoline and LCO were observed whilst at the same time significantly less coke and bottoms (unconverted feed) were produced when using the mesoporous containing FCC catalyst (Figure 21). The selectivity towards gasoline and LCO was even better when employing heavy VGO. These results highlight the role of intracrystalline mesoporosity in zeolites in increasing the accessibility of the feedstock molecules to the active sites - which is evidenced by the more effective conversion of the bottom especially for heavy VGO (Figure 21C) - and in facilitating the ready exit of the intermediates that leads to a significant decrease in the production of coke and an increase of gasoline and LCO. The increased selectivity towards intermediates (gasoline and LCO) is a clear evidence of the role of shorter diffusion path length in reducing overcracking reactions (Figure 20B).

A more realistic description of the various conversions occurring during FCC is given by the six-lump model (Figure 22). Here the conversion of VGO to the different fractions is modeled as a series of parallel and consecutive reactions. In FCC, all light products can be formed directly from the VGO, yet their formation from secondary reaction is also significant. ${ }^{[131]}$ The shortening of the diffusion path length allows for minimizing the occurrence of secondary reactions and thus 
increasing the yield of the desired gasoline and LCO. The model furthermore depicts liquefied petroleum gas (LPG), which is an important fraction of the FCC process. LPG consists of light paraffins (propane and butane) and olefins (propylene and butylene). Whilst olefins represent valuable FCC products, being the starting material for many other transformations, paraffins represent products with rather low economic interest. Indeed, maximizing propylene production has become a major issue in FCC due to an increasing demand/supply imbalance, although different markets have different needs at different times. ${ }^{[132]}$

During the FCC process, olefins transform through hydrogen transfer reaction into the corresponding paraffins. In order to prevent the hydrogen transfer reaction to occur, the residence time of the olefins inside the catalyst must be reduced for example by shortening of the diffusion path length. In a commercial operation in a refinery, ${ }^{[133]}$ a steady increase in LPG olifinicity was observed through replacing the incumbent FCC catalyst by another containing the mesostructured Y zeolite. Commercial data confirmed the observed trend using an equilibrium catalyst from the refinery and analyzed in an ACE unit (Figure 23A). A gradual increase in the LPG olefinicity was also observed at the refinery as the concentration of the FCC catalyst containing mesostructured Y zeolite in the circulating inventory steadily increased (Figure 23B). In this commercial trial, the most important yield shift was the increase in butylene selectivity (Figure 23C). Furthermore, a very valuable increase in gasoline octane was also observed due to a higher concentration of olefins in the lighter gasoline fraction (Figure 23D).

A different commercial trial was carried out at Alon's Big Spring, TX refinery, in which 318 tons of the equilibrium FCC catalyst comprising mesostructured USY zeolite produced by Grace using Rive Technology surfactant-templating technology. ${ }^{[134]}$ The catalyst addition to the FCC unit was of 3 tons/day, which represents the equivalent amount as for the incumbent catalyst. As a result of the improved bottom cracking ability of the FCC catalyst containing the mesostructured zeolite, the operation conditions of the refinery were allowed to be modified through lowering the riser temperature whilst at the same time increasing the feed throughput (Figure 24A). Consequently, a decrease in the temperature of the regenerator was induced, which yet did not affect the regeneration of the catalyst. Throughout the trial the combination of improved coke selectivity whilst increasing feed rate allowed to achieve a significant 
increase in both gasoline (Figure 24B) and LCO production (Figure 24C). The observed selectivity towards intermediates confirms that the introduction of intracrystalline mesoporosity shortens the diffusion path length and hinders the occurrence of secondary reactions. At the end of the commercial trial, the additional value that was delivered to the refinery by replacing the incumbent catalyst with the mesostructured USY containing FCC catalyst was estimated to be over US $\$ 2.50 / \mathrm{bbl}$ of the FCC feed (Figure 24D). This value is well above the catalytic uplift estimated from extensive preliminary testing using an ACE unit (US\$ 2.00/bbl of FCC feed). Sampling of the equilibrium catalyst during the entire duration of the trial, allowed to assess the excellent mechanical and hydrothermal stability of the catalyst containing mesostructured Y zeolite. ${ }^{[135]}$

Several thousand tons of FCC catalyst featuring mesostructured USY zeolite have up to date been produced. The elevated cost of the surfactant-based process could be overcome through improving employed raw materials and operating conditions, which allowed to decrease manufacturing cost by a factor of ten during the up-scaling process. Moreover, it has been shown that the cost of the surfactant-templating process can be substantially minimized by recovering and recycling the surfactant. ${ }^{[136]}$

Building on the successful commercialization of surfactant-templating technology for FCC, new hierarchical zeolites are being produced using this strategy to meet the needs of the refinery industry by providing more flexibility and improved performance in a rapidly changing environment. On this regard, the joint effort between Zeolyst International, CRI/Criterion Inc and Rive Technology for the commercialization of surfactant-templated zeolites as superior hydrocracking catalysts is a major step towards expanding this technology to new refining processes. Currently, surfactant-templated zeolites based on other structures such as ZSM-5, beta, mordenite and chabazite, among other, are being tested in refining, petrochemical and fine chemical applications.

\section{Further perspectives and concluding remarks}

An impressive variety of surfactant-oriented techniques emerged during the past fifteen years aiming at the achievement of mesoporous zeolites and circumventing the drawbacks and limitations of classical zeolites. 
Though various of the surfactant-oriented strategies allow for designing hierarchical zeolites with interconnectivity of the porosities at different length scales, their architectural variety is by far not comparable to the one disclosed for amorphous oxides. Apart from scarce examples of hexagonal ordered mesoporous arrangement that present pore walls featuring short-scale crystallinity, the quest remains opened for designing hierarchical zeolites featuring mesopores organized in different space groups. It is anticipated that the rational design of smart surfactants will allow to overcome this conundrum.

These new and complex hierarchical architectures will require the development and the availability of advanced characterization techniques for concise visualization and qualification of the interconnectivity of porosity at various length scales. Diffusion studies together with advanced computer simulations will allow for disclosing ideal porous architectures and textural properties for given catalytic applications.

Except the post-synthetic zeolite surfactant-templating that is already a commercial reality, no other mesostructuration technique has allowed, so far, to produce hierarchical zeolite that managed to jump on the bandwagon of commercial catalytic applications. The design of new surfactant-oriented processes is expected to foster the use of hierarchical zeolites that will replace conventional catalysts in existing processes opening up new and exciting opportunities.

\section{Acknowledgements}

Authors acknowledge the CAPITA project WAVES (EP7-NMP-266543) and Rive Technology for financial support.

\section{References}

[1] V. Chiola, J. E. Ritsko and C. D. Vanderpool, US Patent 3,556, 725, 1971.

[2] F. Di Renzo, H. Cambon, R. Dutartre, Microporous Mater. 1997, 10, 283.

[3] T. Yanagisawa, T. Shimizu, K. Kuroda, C. Kato, Bull. Chem. Soc. Jpn. 1990, 63, 988.

[4] J. S. Beck, C. T.-W. Chu, I. D. Johnson, C. T. Kresge, M. E. Leonowicz, W. J. Roth, J. W. Vartuli, WO Patent 91/11390, 1991. 
[5] C. T. Kresge, M. E. Leonowicz, W. J. Roth, J. C. Vartuli, J. S. Beck, Nature, 1992, 359, 710 .

[6] J. S. Beck, J. C. Vartuli, W. J. Roth, M. E. Leonowicz, C. T. Kresge, K. D. Schmitt, C. T. W. Chu, D. H. Olson, E. W. Sheppard, S. B. McCullen, J. B. Higgins, J. L. Schlenker, J. Am. Chem. Soc. 1992, 114, 10834.

[7] J. Y. Ying, C. P. Mehnert, M. S. Wong, Angew. Chem. Int. Ed. 1999, 38, 56.

[8] Y. Shi, Y. Wan, D. Zhao, Chem. Soc. Rev. 2011, 40, 3854.

[9] Y. Wan, D. Zhao, Chem. Rev. 2007, 107, 2821.

[10] Q. Huo, D. I. Margolese, U. Ciesla, P. Feng, T. E. Gier, P. Sieger, R. Leon, P. M. Petroff, F. Schüth, G. D. Stucky, Nature 1994, 368, 317.

[11] G. J. A. A. Soler-Illia, C. Sanchez, B. Lebeau, J. Patarin, Chem. Rev. 2002, 102, 4093.

[12] Q. Huo, D. I. Margolese, G. D. Stucky, Chem. Mater. 1996, 8, 1147.

[13] J. Man Kim, Y. Sakamoto, Y. Kyu Hwang, Y.-U. Kwon, O. Terasaki, S.-E. Park, G. D. Stucky, J. Phys. Chem. B 2002, 106, 2552.

[14] A. Blanazs, S. P. Armes, A. J. Ryan, Macromol. Rapid Commun. 2009, 30, 267.

[15] T.-Y. Ma, L. Liu, Z.-Y.Yuan, Chem. Soc. Rev. 2013, 42, 3977.

[16] L.-G. Qui, T. Xu, Z.-Q. Li, W. Wang, Y. Wu, X. Jiang, X.-Y. Tian, L.-D. Zhang, Angew. Chem. Int. Ed. 2008, 47, 9487.

[17] D. Bradshaw, S. El-Hankari, L. Lupica-Spagnolo, Chem. Soc. Rev. 2014, 43, 5431.

[18] K. Cassiers, T. Linssen, M. Mathieu, M. Benjelloun, K. Schrijnemakers, P. Van Der Voort, P. Cool, E. F. Vansant, Chem. Mater. 2002, 14, 2317.

[19] A. Corma. Chem. Rev. 1997, 97, 2373.

[20] K. R. Kloestra, H. van Bekkum, J. C. Jansen, Chem. Commun. 1997, 2281.

[21] M. J. Verhoef, P. J. Kooyman, J. C. van der Waal, M. S. Rigutto, J. A. Peters, H. van Bekkum, Chem. Mater. 2001, 13, 683.

[22] K. Schumacher, P. I. Ravikovitch, A. Du Chesne, A. V. Neimark, K. K. Unger, Langmuir 2000, 16, 4648.

[23] Y. Fang, H. Hu, J. Am. Chem. Soc. 2006, 128, 10636.

[24] J. Garcia Martinez, K. Li (Eds.), Mesoporous Zeolites: Preparation, Characterization and Application, Wiley, 2015. 
[25] J. Perez-Ramirez, C. H. Christensen, K. Egeblad, C. H. Christensen, J. C. Groen, Chem. Soc. Rev. 2008, 37, 2530.

[26] W. J. Roth, P. Nachtigall, R. E. Morris, J. Cejka, Chem. Rev. 2014, 114, 4807.

[27] M. V. Opanasenko, W. J. Rothab, J. Čejka, Catal. Sci. Technol. 2016, 6, 2467.

[28] K. Möller, T. Bein, Chem. Soc. Rev. 2013, 42, 3689.

[29] D. P. Serrano, J. M. Escola, P. Pizarro, Chem. Soc. Rev. 2013, 42, 4004.

[30] S. Lopez-Orozco, A. Inayat, A. Schwab, T. Selvam, W. Schwieger, Adv. Mater. 2011, 23, 2602.

[31] C. J. H. Jacobsen, C. Madsen, J. Houzvicka, I. Schmidt, A. Carlsson, J. Am. Chem. Soc. 2000, 122, 7116.

[32] R. Chal, C. Gérardin, M. Bulut, S. van Donk, ChemCatChem 2011, 3, 67.

[33] K. R. Kloetstra, H. W. Zandbergen, J. C. Jansen, H. van Bekkum, Microporous Mater. 1996, 6, 287.

[34] A. Karlsson, M. Stocker, R. Schmidt, Micropor. Mesopor. Mater. 1999, 27, 181.

[35] S. Du, F. Li, Q. Sun, N. Wang, M. Jia, J. Yu, Chem. Commun. 2016, 52, 3368.

[36] J. Zhu, Y. Zhu, L. Zhu, M. Rigutto, A. van der Made, C. Yang, S. Pan, L. Wang, L. Zhu, Y. Jin, Q. Sun, Q. Wu, X. Meng, D. Zhang, Y. Han, J. Li, Y. Chu, A. Zheng, S. Qiu, X. Zheng, F.-S. Xiao, J. Am. Chem. Soc. 2014, 136, 2503.

[37] F.-S. Xiao, L. Wang, C. Yin, K. Lin, Y. Di, J. Li, R. Xu, D. S. Su, R. Schlögl, T. Yokoi, T. Tatsumi, Angew. Chem. Int. Ed. 2006, 45, 3090.

[38] F. Liu, T. Willhammar, L. Wang, L. Zhu, Q. Sun, X. Meng, W. CarrilloCabrera, X. Zou, F.-S. Xiao, J. Am. Chem. Soc. 2012, 134, 4557.

[39] J.-Y. Liu, J.-G. Wang, N. Li, H. Zhao, H.-J. Zhou, P.-C.Sun, T.-H. Chen, Langmuir 2012, 28, 8600.

[40] H. Wang, T. J. Pinnavaia, Angew. Chem. Int. Ed. 2006, 45, 7603.

[41] S. R. Stojkovic, B. Adnadjevic, Zeolites 1988, 6, 523.

[42] Y. Liu, W.Z. Zhang, T. J. Pinnavaia, J. Am. Chem. Soc. 2000, 122, 8791.

[43] Y. Liu, W. Zhang, T. J. Pinnavaia, Angew. Chem. 2001, 113, 1295; Angew. Chem. Int. Ed. 2001, 40, 1255. 
[44] Z. Zhang, Y. Han, F.-S.Xiao, S. Qiu, L. Zhu, R. Wang, Y. Yu, Z. Zhang, B. Zou, Y. Wang, H. Sun, D. Zhao, Y. Wei, J. Am. Chem. Soc. 2001, 123, 5014.

[45] Z. Zhang, Y. Han, L. Zhu, R. Wang, Y. Yu, S. Qiu, D. Zhao, F.-Shou Xiao, Angew. Chem. Int. Ed. 2001, 40, 1258.

[46] P. Li, G. Xiong, L. Liu, L. Wang, Spectrochim. Acta Mol. Biomol. Spectrosc. 2013, 107, 218.

[47] P. Li, L. P. Liu, G. Xiong, Phys. Chem. Chem. Phys. 2011, 13, 11248.

[48] Y. Liu, T. J. Pinnavaia, J. Mater. Chem. 2004, 14, 3416.

[49] Q. Huo, R. Leon, P. M. Petroff, G. D. Stucky, Science 1995, 268, 1324.

[50] Y. Liu, T. J. Pinnavaia, Chem. Mater. 2002, 14, 3.

[51] D. H. Park, S.-S. Kim, T. J. Pinnavaia, F. Tzompantzi, J. Prince, J. S. Valente, J. Phys. Chem. C 2011, 115, 5809.

[52] F. N. Gu, F. Wei, J. Y. Yang, N. Lin, W. G. Lin, Y. Wang, J. H. Zhu, Chem. Mater. 2010, 22, 2442.

[53] Y. Zhu, Z. Hua, J. Zhou, L. Wang, J. Zhao, Y. Gong, W. Wu, M. Ruan, J. Shi, Chem. Eur. J. 2011, 17, 14618.

[54] X. Zhou, H. Chen, Y. Zhu, Y. Song, Y. Chen, Y. Wang, Y. Gong, G. Zhang, Z. Shu, X. Cui, J. Zhao, J. Shi, Chem. Eur. J. 2013, 19, 10017.

[55] A. Sachse, C. Wuttke, E. Lissner, M. O. de Souza, Chem. Eur. J. 2014, 20, 14996.

[56] T. Wang, H. Kaper, M. Antonietti, B. Smarsly, Langmuir 2007, 23, 1489.

[57] S. Liu, X. Cao, L. Li, C. Li, Y. Ji, F.-S. Xiao, Colloids Surf. A 2008, 318, 269.

[58] J. Song, L. Ren, C. Yin, Y. Ji, Z. Wu, J. Li, F.-S. Xiao, J. Phys. Chem. C 2008, 112, 8609 .

[59] M. Thommes, B. Smarsly, M. Groenewolt, P. I. Ravikovitc, A. V. Neimark, Langmuir 2006, 22, 756.

[60] D. P. Serrano, J. Aguado, J. M. Escola, J. M. Rodriguez, A. Peral, Chem. Mater. 2006, 18, 2462.

[61] D. P. Serrano, J. Aguado, G. Morales, J. M. Rodriguez, A. Peral, M. Thommes, J. D. Epping, B. F. Chmelka, Chem. Mater. 2009, 21, 641.

[62] J. Aguado, D. P. Serrano, J. M. Rodriguez, Micropor. Mesopor. Mater. 2008, 115, 504. 
[63] M. Choi, H. S. Cho, R. Srivastava, C. Venkatesan, D.-H. Choi, R. Ryoo, Nature Mater. 2006, 5, 718.

[64] K. Cho, R. Ryoo, S. Asahina, C. Xiao, M. Klingstedt, A. Umemura, M. W. Anderson, O. Terasaki, Solid State Sci. 2011, 13, 750.

[65] G. V. Shanbhag, M. Choi, J. Kim, R. Ryoo, J. Catal. 2009, 264, 88.

[66] M. Choi, R. Srivastava, R. Ryoo, Chem. Commun. 2006, 4380.

[67] A. Inayat, I. Knoke, E. Spiecker, W. Schwieger, Angew. Chem. Int. Ed. 2012, 51, 1962.

[68] M. Qamar, I. Baig, A.-M. Azad, M. I. Ahmed, M. Qamaruddin, Chem. Eng. J. 2016, 290, 282.

[69] K. Cho, H. S. Cho, L.-C.de Ménorval, R. Ryoo, Chem. Mater. 2009, 21, 5664.

[70] J. Han, D. Liu, Chem. Lett. 2015, 44, 992.

[71] J. Han, D. Liu, Eur. J. Inorg. Chem. 2015, 5081.

[72] M. Choi, K. Na, J. Kim, Y. Sakamoto, O. Terasaki, R. Ryoo, Nature 2009, $461,246$.

[73] K. Na, M. Choi, W. Park, Y. Sakamoto, O. Terasaki, R. Ryoo, J. Am. Chem. Soc. 2010, 132, 4169.

[74] R. J. Messinger, K. Na, Y. Seo, R. Ryoo, B. F. Chmelka, Angew. Chem. Int. Ed. 2015, 54, 927.

[75] B. Liu, K. Xie, S. C. Oh, D. Sun, Y. Fang, H. Xi, Chem. Eng. Sci. 2016, 153, 374.

[76] C. Li, Y. Ren, J. Gou, B. Liu, H. Xi, Appl. Surf. Sci. 2017, 392, 785.

[77] K. Na, C. Jo, J. Kim, K. Cho, J, Jung, Y. Seo, R. J. Messinger, B. F. Chmelka, R. Ryoo, Science 2011, 333, 328.

[78] L. Wu, V. Degirmenci, P. C. M. M. Magusin, B. M. Szyja, E. J. M. Hensen, Chem. Commun. 2012, 48, 9492.

[79] J. Jung, C. Jo, K. Cho, R. Ryoo, J. Mater. Chem. 2012, 22, 4637.

[80] D. Xu, S. Che, O. Terasaki, New J. Chem. 2016, 40, 3982.

[81] D. Xu, J. Feng, S. Che, Dalton Trans. 2014, 43, 3612.

[82] D. Xu, Y. Ma, Z. Jing, L. Han, B. Singh, J. Feng, X. Shen, F. Cao, P. Oleynikov, H. Sun, O. Terasaki, S. Che, Naure Commun. 2014, 5, 4262.

[83] B. K. Singh, D. Xu, L. Han, J. Ding, Y. Wang, S. Che, Chem. Mater. 2014, 26,7183 . 
[84] D. Verboekend, N. Nuttens, R. Locus, J. Van Aelst, P. Verolme, J. C. Groen, J. Perez-Ramirez, B. F. Sels, Chem. Soc. Rev. 2016, 45, 3564.

[85] Y. Goto, Y. Fukushima, P. Ratu, Y. Imada, Y. Kubota, Y. Sugi, M. Ogura, M. Matsukata, J. Porous Mater. 2002, 9, 43.

[86] I. I. Ivanova, A. S. Kuznetsov, V. V. Yuschenko, E. E. Knyazeva, Pure Appl. Chem. 2004, 76, 1647.

[87] I. A. Kasyanova, A. A. Maerle, I. I. Ivanova, V. I. Zaikovskii, J. Mater. Chem. A 2014, 2, 16978.

[88] I. I. Ivanova, E. E. Knyazeva, Chem. Soc. Rev. 2013, 42, 3671.

[89] I. I. Ivanova, I. A. Kasyanov, A. A. Maerle, V. I. Zaikovskii, Microporous Mesoporous Mater. 2014, 189, 163.

[90] V. V. Ordomskii, Y. V. Monakhova, E. E. Knyazeva, N. S. Nesterenko, I. I. Ivanova, Russ. J. Phys. Chem. A 2009, 83, 1012.

[91] B. Boukoussa, N. Aouad, R. Hamacha, A. Bengueddach, J. Phys. Chem. Sol. 2015, 78, 78 .

[92] S. Liu, J. Ren, H. Zhang, E. Lv, Y. Yang, Y.-W. Li, J. Catal. 2016, 335, 11.

[93] J. Na, G. Liu, T. Zhou, G. Ding, S. Hu, L. Wang, Catal. Lett. 2013, 143 , 267.

[94] N. Wilde, M. Pelz, S. G. Gebhardt, R. Gläse, Green Chem. 2015, 17, 3378.

[95] C.-G. Li, Y. Lu, H. Wu, P. Wu, M. He, Chem. Commun. 2015, 51, 14905.

[96] J. Y. Ying, J. Garcia-Martinez, US Patent, US20070244347 A1, 2005.

[97] J. Garcia-Martinez, M. Johnson, J. Valla, K. Li, J. Y. Ying, Catal. Sci. Technol. 2012, 2, 987.

[98] R. Chal, T. Cacciaguerra, S. van Donk, C. Gérardin, Chem. Commun. 2010, 46,7840 .

[99] K. Li, J. Valla, J. Garcia Martinez, ChemCatChem 2014, 6, 46.

[100] N. Linares, A. Sachse, E. Serrano, A. Grau-Atienza, E. Oliveira Jardim, J. Silvestre-Albero, M. A. Liutheviciene Cordeiro, F. Fauth, G. Beobide, O. Castillo, J. García-Martínez, Chem. Mater. 2016, DOI: 10.1021/acs.chemmater.6b03688.

[101] J. Wu, H. Shan, W. Chen, X. Gu, P. Tao, C. Song, W. Shang, T. Deng, Adv. Mater. 2016, DOI: 10.1002/adma.201602519.

[102] D. Verboekend, M. Milina, S. Mitchell, J. Perez-Ramirez, Cryst. Growth Des. 2013, 13, 5025. 
[103] T. Prasomsri, W. Jiao, S. Z. Weng, J. Garcia Martinez, Chem. Commun. 2015, 51, 8900 .

[104] M. S. Holm, M. K. Hansen, C. H. Christensen, Eur. J. Inorg. Chem. 2009, 1194.

[105] J. Garcia-Martinez, M. M. Johnson, I. Valla, US patent, 20100196263, 2010.

[106] A. Galarneau, F. Villemot, J. Rodriguez, F. Fajula, B. Coasne, Langmuir 2014, 30, 13266.

[107] A. Sachse, C. Wuttke, U. Díaz, M. Oberson de Souza, Micropor. Mesopor. Mater. 2015, $217,81$.

[108] S. Mitchell, A. B. Pinar, J. Kenvin, P. Crivelli, J. Kräger, J. Perez-Ramirez, Nature Commun. 2015, 6, 1.

[109] M. Thommes, K. Kaneko, A. V. Neimark, J. P. Olivier, F. RodriguezReinoso, J. Rouquerol, K. S. W. Sing, Pure Appl. Chem. 2015, 87, 1051.

[110] M. Thommes, K. A. Cychosz, Adsorption 2014, 20, 233.

[111] C. J. Rasmussen, A. Vishnyakov, M. Thommes, B. M. Smarsly, F. Kleitz, A. V. Neimark, Langmuir 2010, 26, 10147.

[112] J. Zecevic, C. J. Gommes, H. Friedrich, P. E. de Jongh, K. P. de Jong, Angew. Chem. Int. Ed. 2012, 51, 4213.

[113] Y. Wei, T. E. Parmentier, K. P. de Jong, J. Zecevic, Chem. Soc. Rev. 2015, $44,7234$.

[114] W. Wan, J. Sun, J. Su, S. Hovmoller, X. Zou, J. Appl. Crystallogr. 2013, 46, 1863.

[115] T. Willhammar, Y. Yun, X. Zou, Adv. Funct. Mater. 2014, 24, 182.

[116] J. M. Thomas, R. K. Leary, Angew. Chem. Int. Ed. 2014, 53, 12020.

[117] J. Garcia-Martinez, C. Xiao, K.A. Cychosz, K. Li, W. Wan, X. Zou, M. Thommes, ChemCatChem 2014, 6, 3110.

[118] A. Galarneau, F. Guenneau, A. Gedeon, D. Mereib, J. Rodriguez, F. Fajula, B. Coasne, J. Phys. Chem. C 2016, 120, 1562.

[119] D. Verboekend, J. Pérez-Ramírez, Catal. Sci. Technol. 2011, 1, 879.

[120] S. Mitchell, M. Milina, R. Verel, M. Hernandez-Rodriguez, A. B. Pinar, L. B. McCusker, J. Perez-Ramirez, Eur. Chem. J. 2015, 21, 14156.

[121] R. J. Gorte, Catal. Lett. 1999, 62, 1.

[122] W. E. Farneth, R. J. Gorte, Chem. Rev. 1995, 95, 615. 
[123] A. Corma, M. S. Grande, V. Gonzalez-Alfaro, A. V. Orchilles, J. Catal. 1996, 159, 375 .

[124] J. Garcia Martinez, K. Li, G. Krishnaiah, Chem. Commun. 2012, 48, 11841.

[125] M. Hartmannm A. G. Machoke, W. Schwieger, Chem. Soc. Rev. 2016, 45, 3313.

[126] W. Vermeiren, J.-P. Gilson, Top. Catal. 2009, 52, 1131.

[127] E. T. C. Vogt, B. M. Weckhuysen, Chem. Soc. Rev. 2015, 44, 7342.

[128] M. A. Camblor, A. Corma, A. Martinez, F. A. Mocholi, J. Perez Pariente, Appl. Catal. 1989, 55, 65.

[129] A. Corma, Catal. Lett. 1993, 22, 33.

[130] K. Rajagopalan, A. W. Peters, G. C. Edwards, Appl. Catal. 1986, 23, 69.

[131] M. Heydari, H. AleEbrahim, B. Dabir, Am. J. Appl. Sci. 2010, 7, 71.

[132] A. Akah, M. Al-Ghrami, Appl. Petrochem. Res. 2015, 5, 377.

[133] A. Humphries, C. Cooper, J. Seidel, Increasing Butylenes Production from the FCC Unit through Rive's Molecular Highway ${ }^{T M}$ Technology, AM-15-32.

[134] G. Krishnaiah, B. Speronello, A. Hansen, J. Crosby, American Fuels and Petrochemical Maufacturers Annual Meeting, San Antonio, TX, 2013.

[135] B. Speronello, J. Garcia-Martinez, A. Hansen R. Hu, Refin. Oper. 2011, $2,1$.

[136] J. Garcia Martinez, M. Johnson, US Patent US8206498, 2012. 


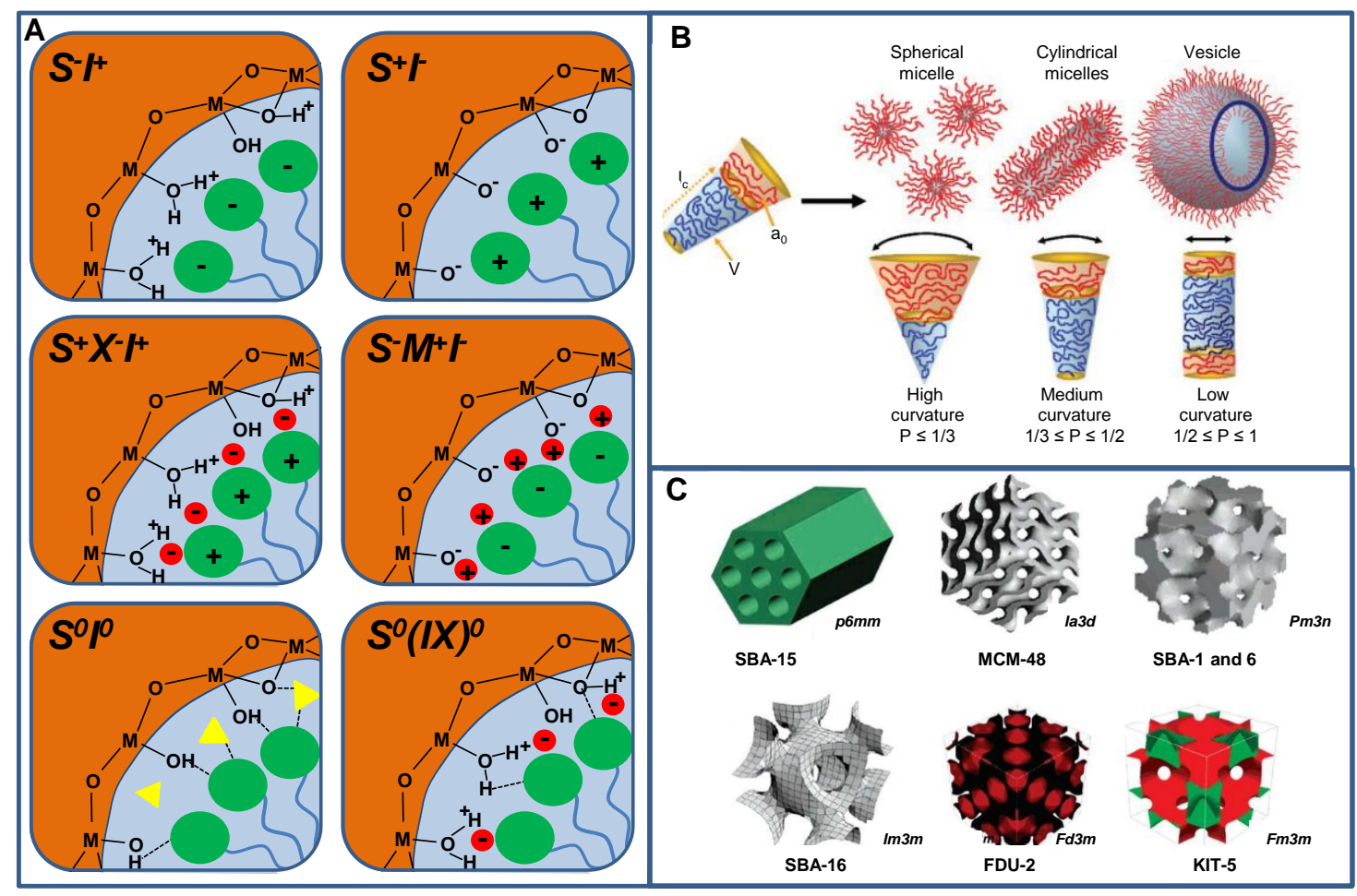

Figure 1. Key concepts of surfactant-templating. Summary of the different chemical interactions leading to mesostructured materials (A). Influence of the mesoporous architecture by the micellar packing parameter (B). Examples of the diversity of mesoporous architectures of amorphous silica (C). Adapted with permission from ref. 9, 11 and 14 . 


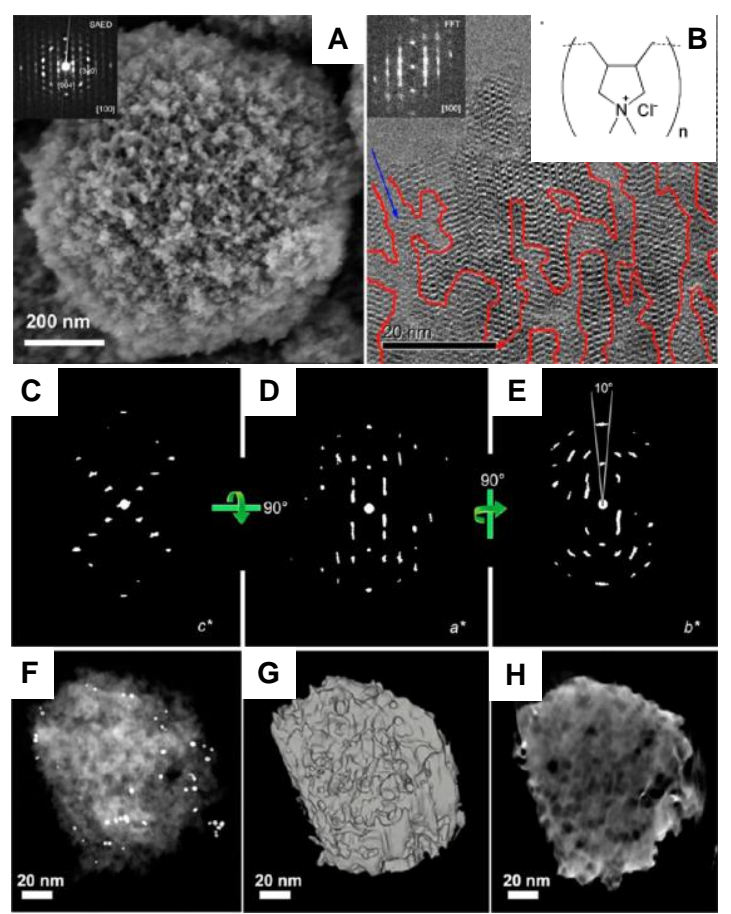

Figure 2. SEM (A) and TEM (B) micrographs of mesoporous *BEA obtained through the employment of PDADMAC. Inset: The chemical structure of PDADMAC. Reconstructed reciprocal lattice of the mesoporous *BEA projected along the $\mathrm{c}^{*}(\mathrm{C}), \mathrm{a}^{*}(\mathrm{D})$ and $\mathrm{b}^{*}(\mathrm{E})$ directions. Representative HAADF-STEM image of mesoporous $*$ BEA selected from a tilting series over a range from $-75^{\circ}$ to $+75^{\circ}$ at regular intervals of $1^{\circ}(\mathrm{F})$. Reconstructed morphology of Beta-MS from HAADF-STEM tomography visualized by surface rendering (G). A slice to the [001] direction extracted from the reconstructed volume $(\mathrm{H})$. Adapted with permission from ref. 36 . 


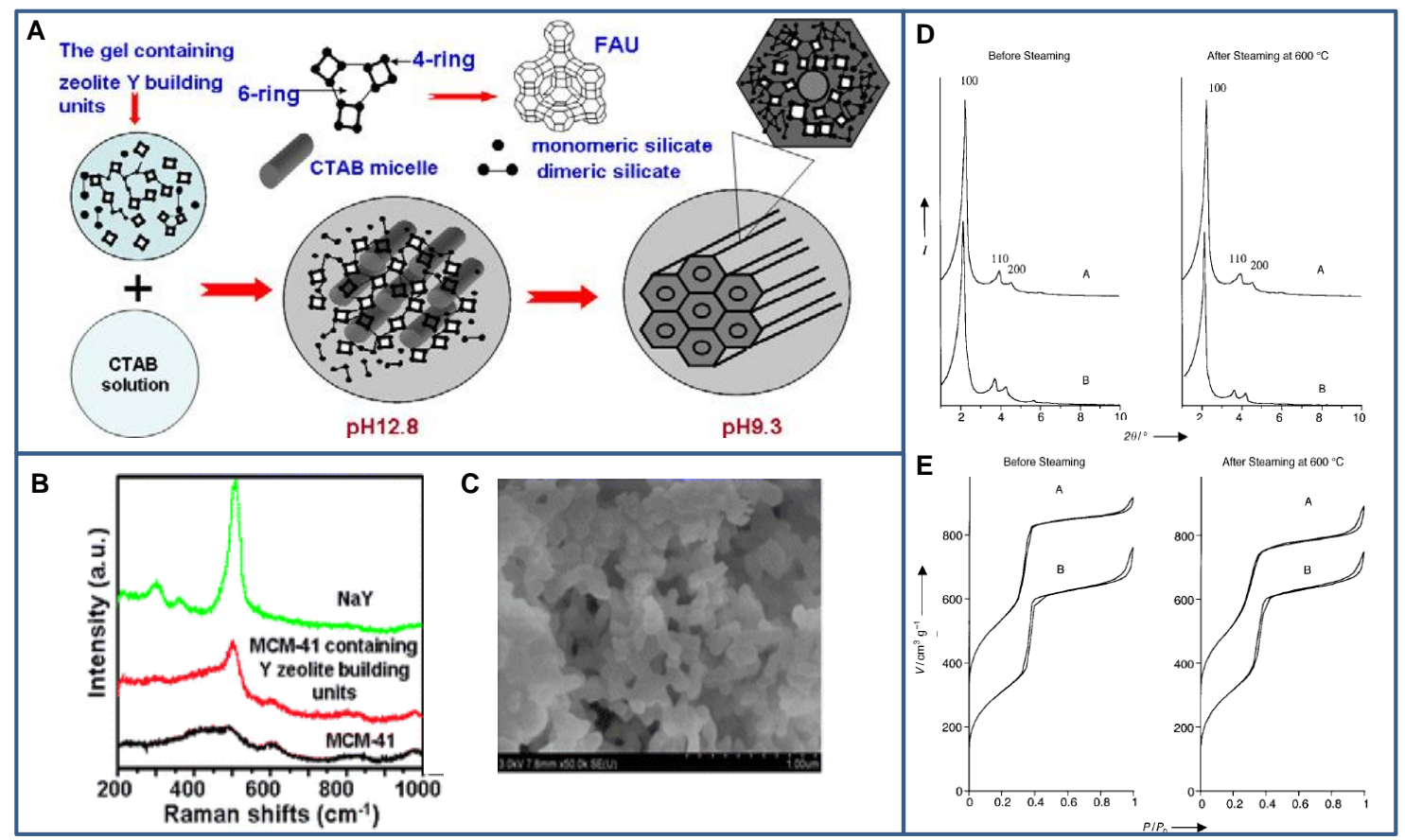

Figure 3. Schematic representation of the formation of Al-MSU-S materials (A). Evidence of the presence of zeolite Y building units by Raman spectroscopy (B). SEM images of AlMSU-S (C). XRD patterns (D) and $\mathrm{N}_{2}$ adsorption and desorption isotherms at $77 \mathrm{~K}(\mathrm{E})$ before and after steaming $\left(600{ }^{\circ} \mathrm{C}, 5 \mathrm{~h}\right)$ of mesoporous aluminosilicates Al-MSU-S $\mathrm{SFI}_{\mathrm{MFI}}$ prepared with ZSM-5 seeds (A) and Al-MSU-S Adapted with permission from ref. 43, 46 and 47. 


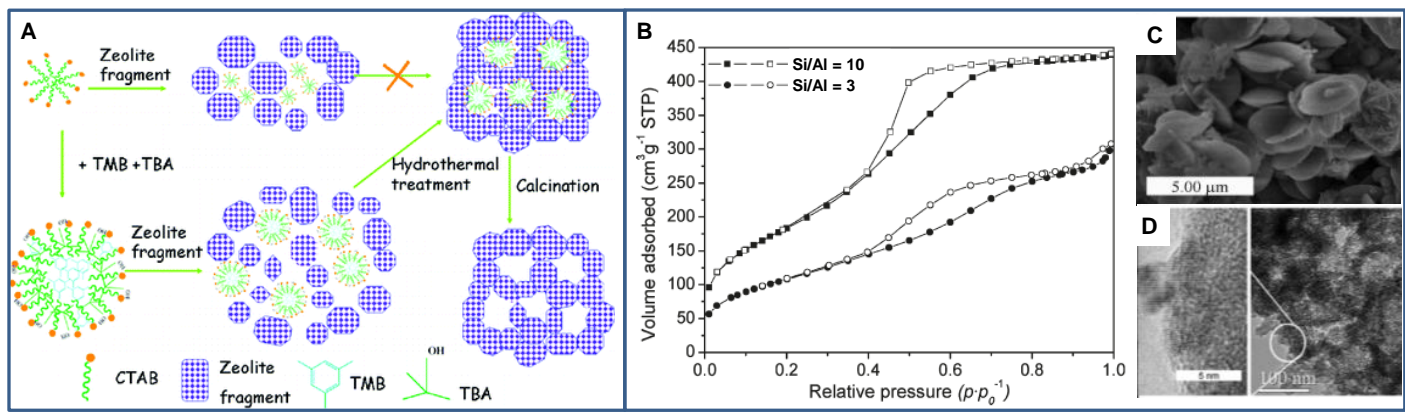

Figure 4. Schematic representation of the mechanism leading to the formation of mesoporous zeolites (A). Nitrogen adsorption and desorption isotherms at $77 \mathrm{~K}$ of mesoporous FAU with variation of Si/Al ratio in the synthesis mixture (B). SEM (C) and TEM (D) images of hierarchical FAU. Adapted with permission from ref. 52. 


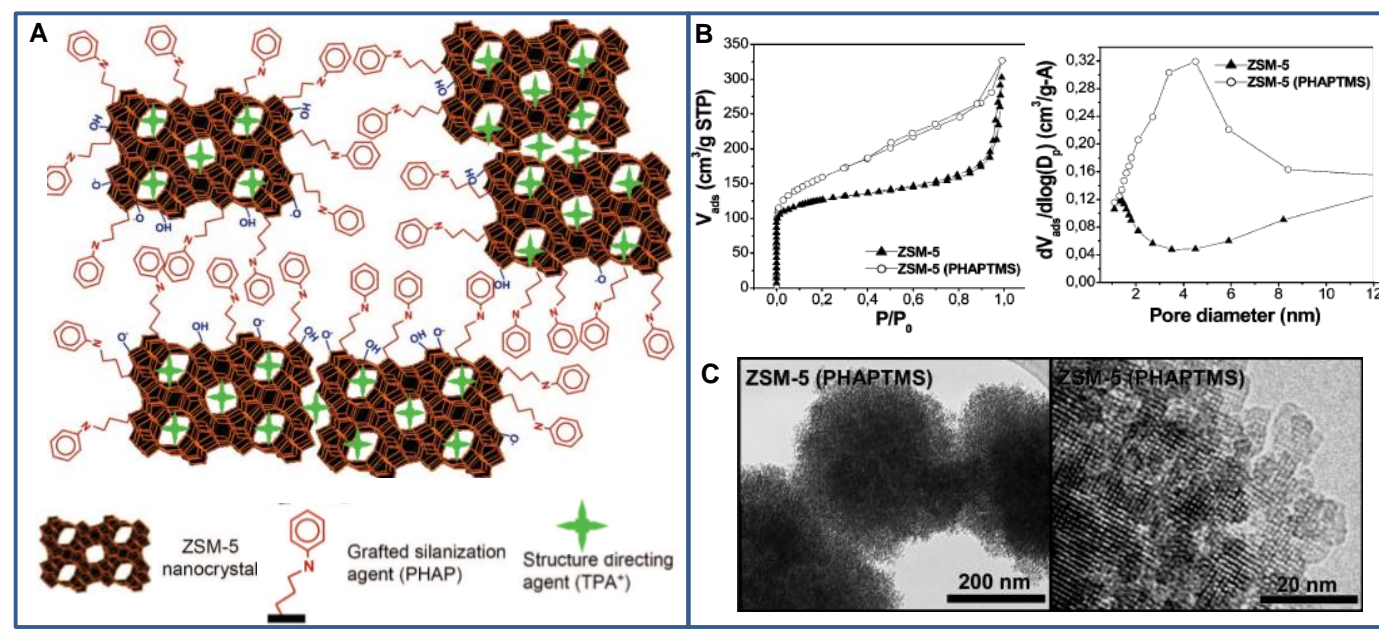

Figure 5. Schematic representation of the ZSM-5 zeolite subunits functionalized with phenylaminopropyl groups (A). Nitrogen adsorption and desorption isotherms at $77 \mathrm{~K}$ and BJH pore size distribution of mesoporous ZSM-5 and bulk ZSM-5 (B). TEM micrographs of mesoporous ZSM-5 (C). Adapted with permission from ref. 60 and 61. 

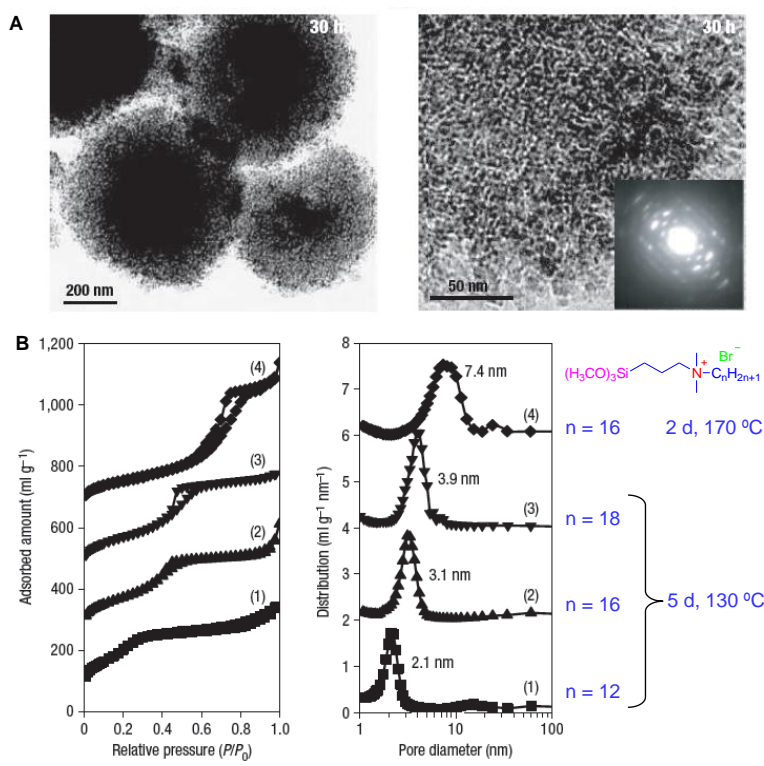

Figure 6. TEM micrographs (A) and nitrogen physisorption isotherms at $77 \mathrm{~K}$ and $\mathrm{BJH}$ pore size distribution (B) of mesoporous ZSM-5 obtained with surfactants of various chain lengths. Adapted with permission from ref. 63 and 69. 


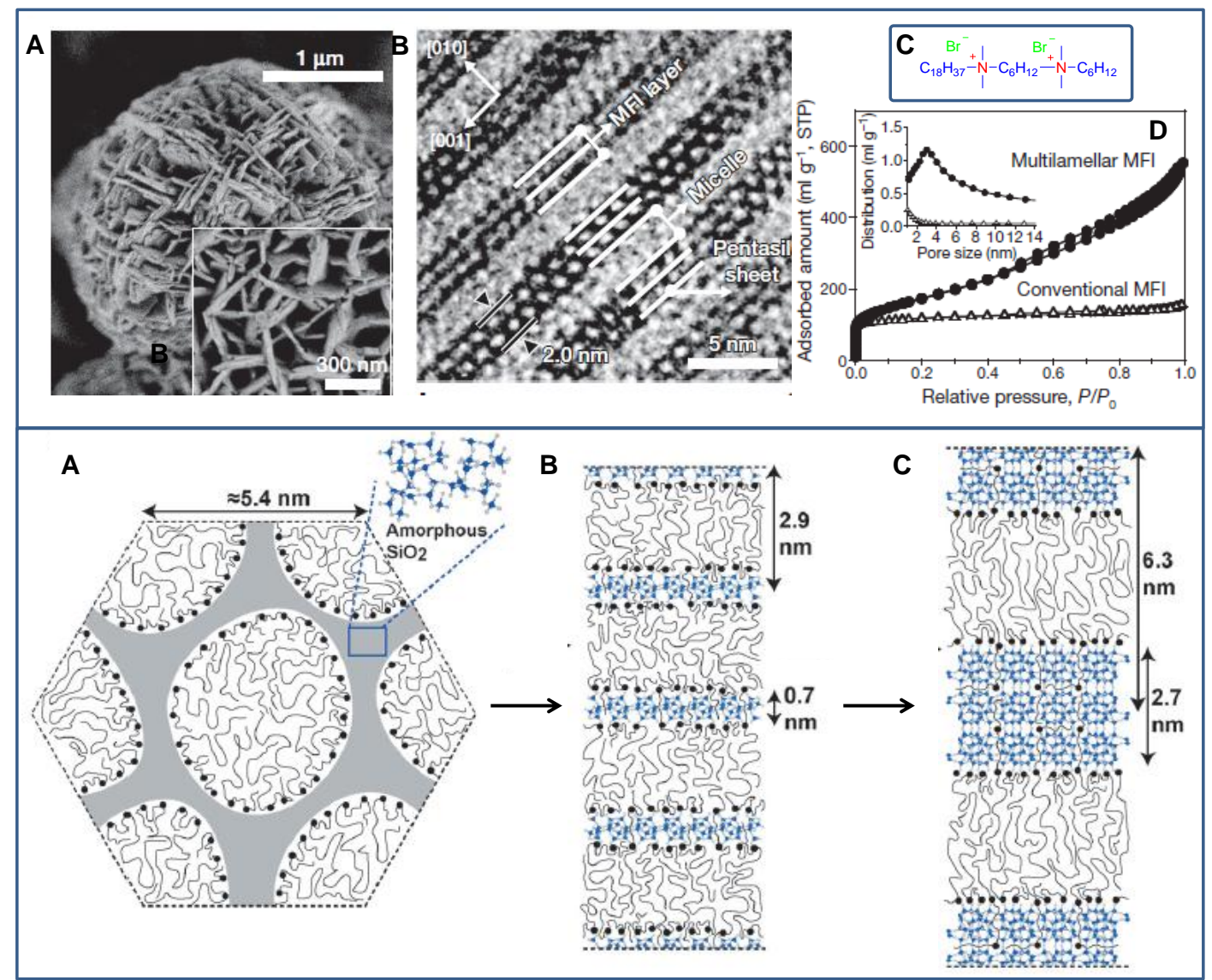

Figure 7. Top: SEM (A) and TEM (B) images of mesoporous MFI nanosheet assemblies. Chemical structure of $\mathrm{C}_{22} \mathrm{H}_{45}-\mathrm{N}\left(\mathrm{CH}_{3}\right)_{2}-\mathrm{C}_{6} \mathrm{H}_{12}-\mathrm{N}\left(\mathrm{CH}_{3}\right)_{2}-\mathrm{C}_{6} \mathrm{H}_{13} \mathrm{Br}_{2}$ (C). Nitrogen adsorption and desorption isotherm at $77 \mathrm{~K}$ for bulk MFI and mesoporous MFI nanosheets (D). Bottom: Schematic representation of the development of the atomic and mesoscopic structure during the synthesis of MFI nanosheets. Initially amorphous silica framework (gray) with weak hexagonal mesoporous ordering (A). Intermediate nanolayered silicates (B) and zeolite MFI nanosheets (C). Blue and white spheres: Si and $\mathrm{O}$ framework atoms, respectively. Black circles and gray lines: surfactant headgroups and alkyl chain length, respectively. Adapted with permission from ref. 72 and 74 . 


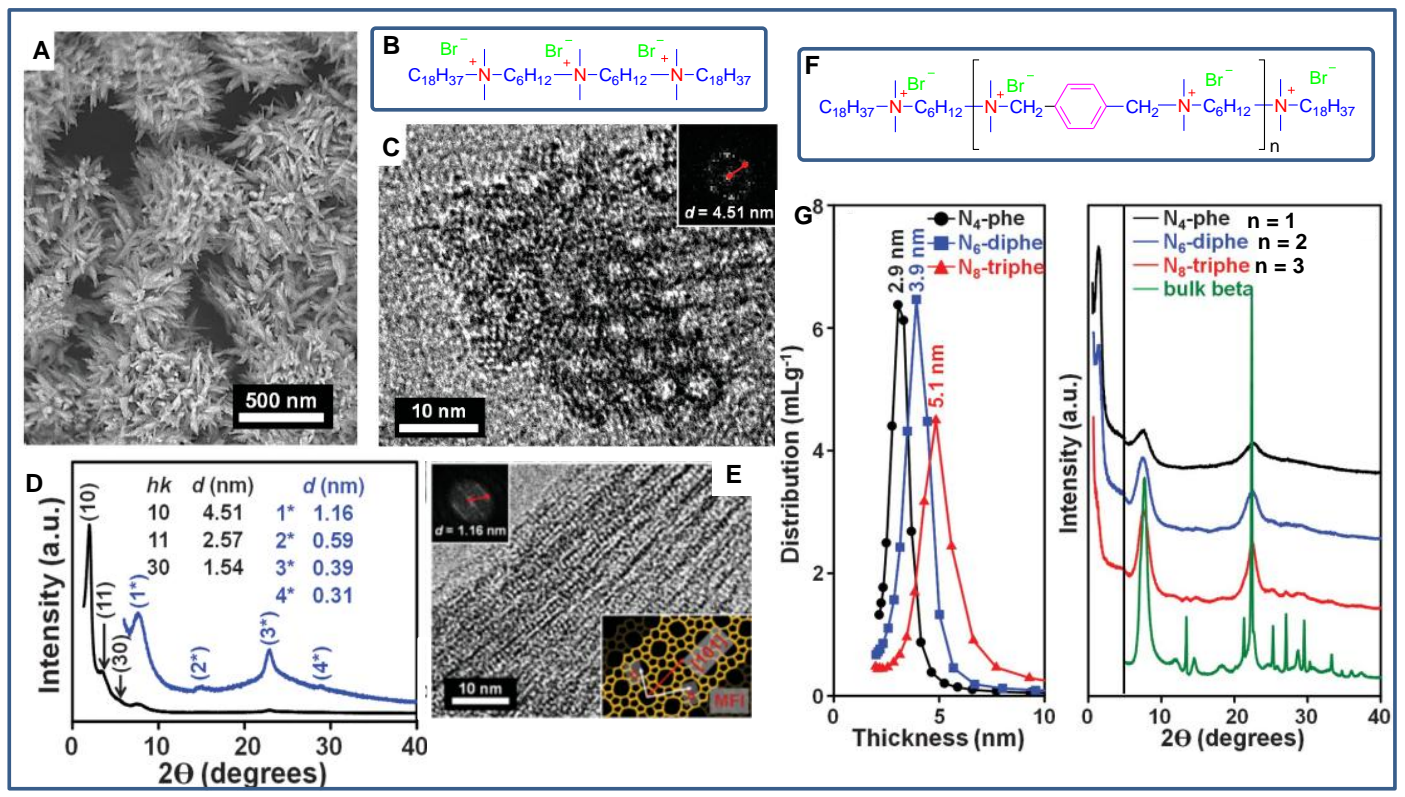

Figure 8. SEM (A) and TEM (C and E) micrographs of hierarchical materials obtained through the use of multicationic surfactants. Insets in $\mathrm{C}$ and $\mathrm{E}$ are the FFT of these micrographs. Chemical structure of the tricationic surfactant $18-\mathrm{N}_{3}-18$ (B). Low and wide angle XRD patterns of achieved materials (D). Structure of the multicationic surfactants featuring aromatic groups $(\mathrm{F})$. Framework thickness and XRD patterns of materials prepared with $\mathrm{N}_{4}$-phe, $\mathrm{N}_{6}$-diphe and $\mathrm{N}_{8}$-triphe. Adapted with permission from ref. 77. 


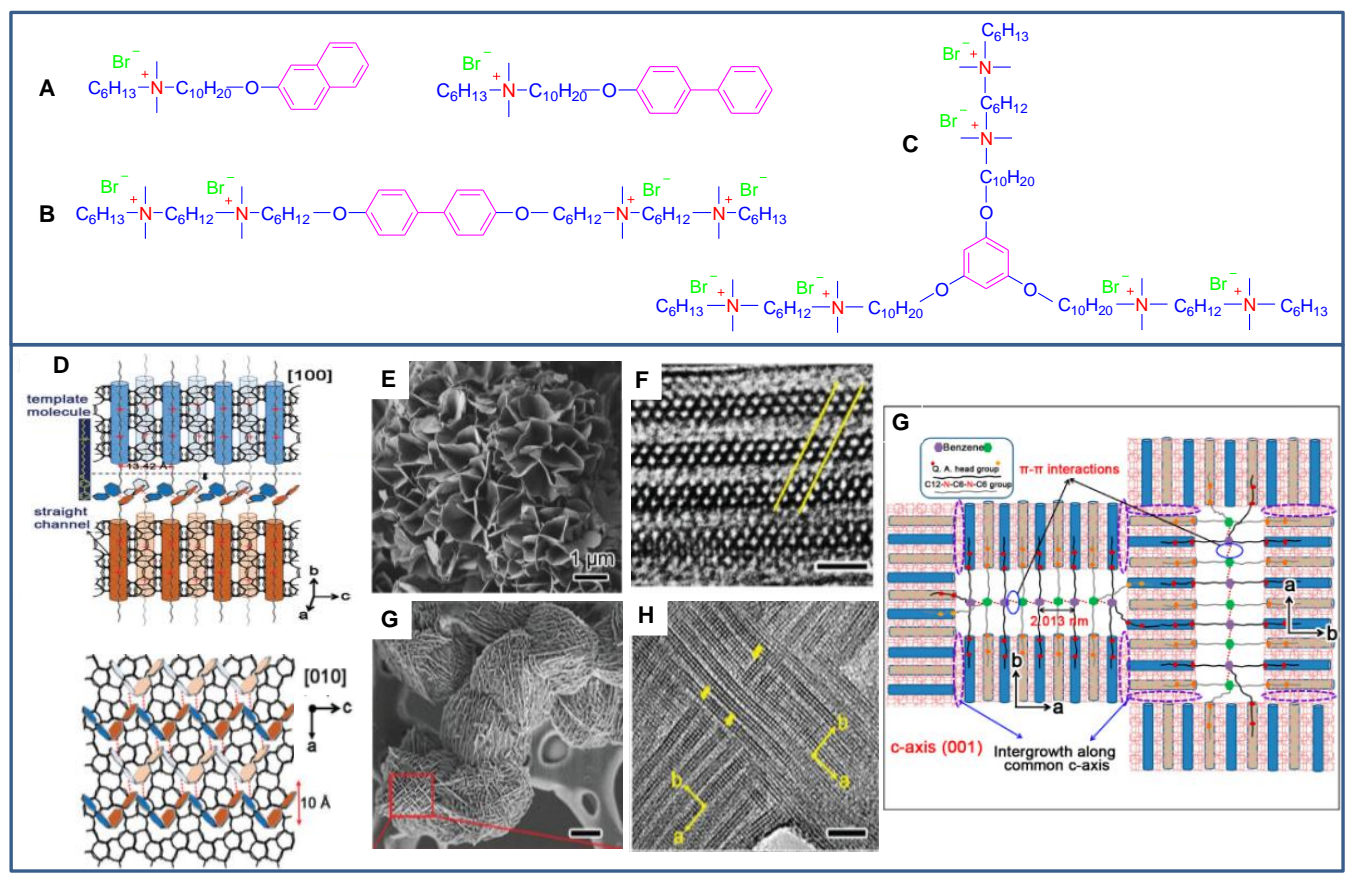

Figure 9. Design concept for the achievement of mesoporous ZSM-5 zeolite. Top: Structures of designed surfactants. Structure of ammonium-based surfactants ended by aromatic groups (A). Bolaform surfactant (B). Triply branched multi cationic surfactants with aromatic center (C). Bottom: Schematic representation of the formation of the nanosheet structure build up through $\pi-\pi$ interactions of surfactants depicted in A (D) . SEM (E) and TEM (F) micrographs of hierarchical zeolites synthetized with surfactants depicted in A. SEM (G) and TEM (H) micrographs of hierarchical zeolite synthetized with Bolaform surfactant depicted in B. Schematic representation of the formation of three dimensional mesopores zeolites through $\pi$ - $\pi$ stacking of surfactant cores depicted in $\mathrm{C}$ (G). Adapted with permission from ref. 82 and 83. 


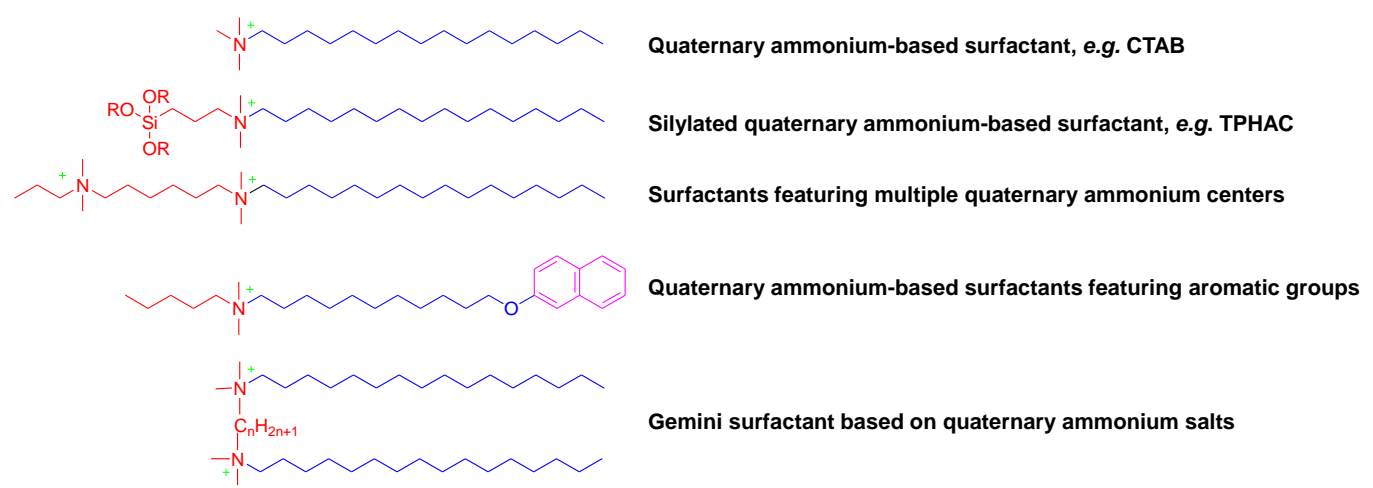

Figure 10. Structures of selected cationic surfactants employed in the development of hierarchical zeolites. 


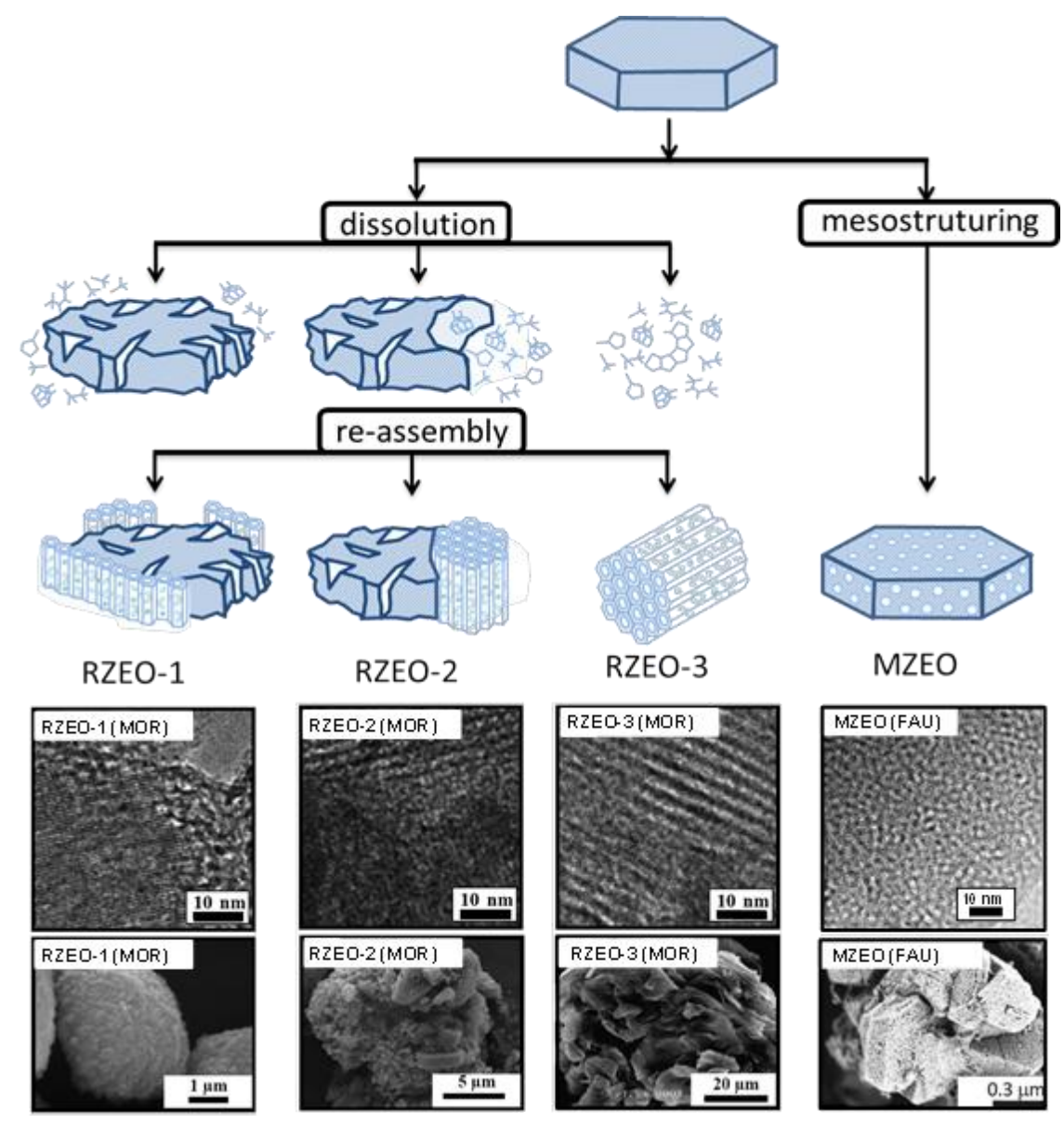

Figure 11. Schematic representation of the post-synthetic approaches using a base and surfactant. On the left side the zeolite recrystallization approach leading to the composite materials RZEO-1, -2 and -3 . On the right side the post-synthetic surfactant templating leading to mesoporous zeolites (MZEO). At the bottom TEM and SEM micrographs of the various materials. Adapted with permission form ref. 88 and 99. 


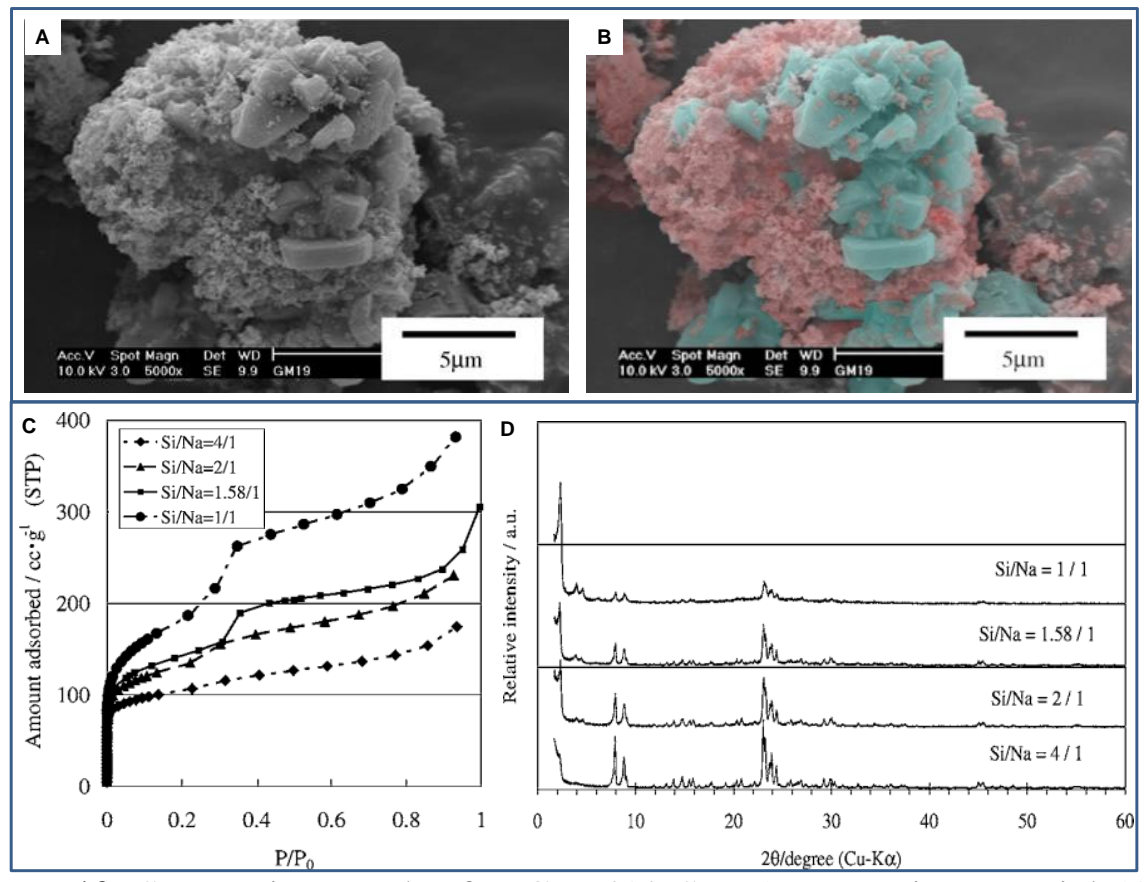

Figure 12. SEM micrograph of MCM-41/ZSM-5 composite material (A). False colored version of the original SEM micrograph, where the amorphous MCM-41 (orange) and crystalline (green) phases are distinguished (B). Nitrogen adsorption and desorption isotherms at $77 \mathrm{~K}$ (D) and XRD patterns of composite materials synthetized with different zeolite/ $\mathrm{NaOH}$ ratios. Adapted with permission from ref. 85 . 


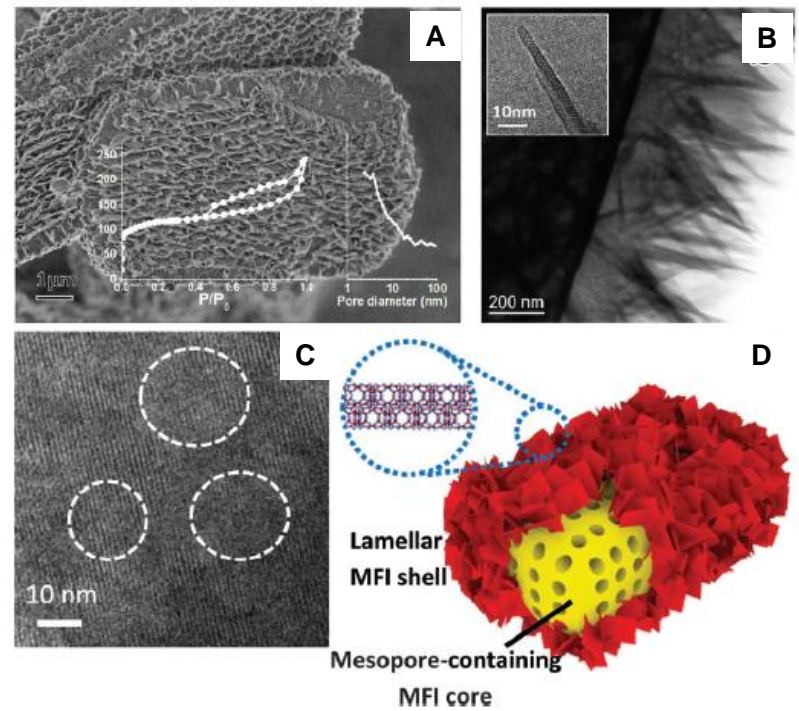

Figure 13. SEM (A), TEM micrographs (B and C) and schematic representation (D) of the composite titanosilicates featuring the core/shell intersection and the irregular intracrystalline mesoporosity. Reprinted with permission from ref. 95. 


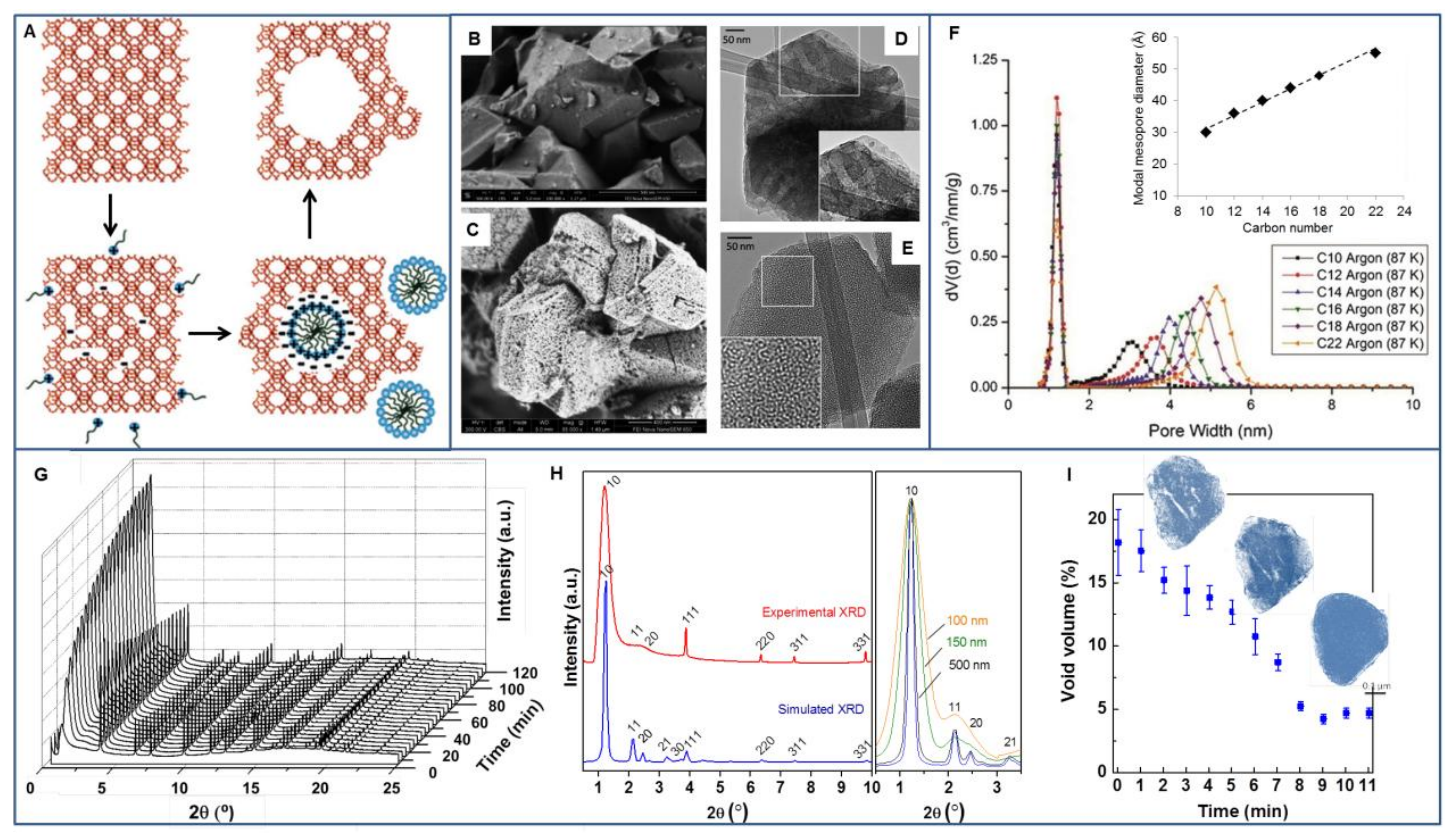

Figure 14. Schematic representation of the proposed mechanism of the post-synthetic zeolite surfactant-templating (A). FESEM micrographs of parent $\mathrm{NaY}$ (B) and mesostructured Y (C). TEM micrographs of parent USY (D) and mesostructured USY (E). NLDFT pore size distribution curves calculated from Ar isotherms at $87 \mathrm{~K}$ for mesoporous zeolites obtained with trimethylalkylammonium-based surfactants with increasing alkyl chin length $\left(\mathrm{C}_{10}-\mathrm{C}_{22}\right)(\mathrm{F})$. Inset: linear correlation between mesopore diameter and number of carbon atoms in the surfactant chain. In situ time resolved synchrotron XRD study of USY zeolite surfactant-templating (G). Simulated XRD pattern (blue) based on the model shown in (a) and experimental (red) XRD of USY zeolite surfactant-templated. $(\mathrm{H})$. Evolution of the void volume of the steamed porosity inparent zeolite throughout surfactant-templating (I). Adapted with permission from ref. 100 and 117. 

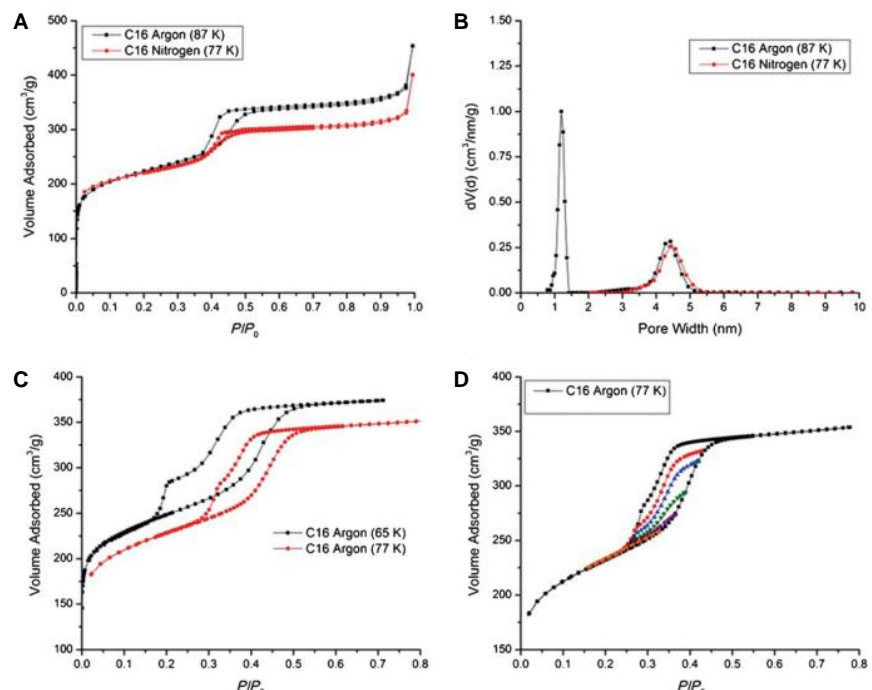

Figure 15. Gas physisorption experiments on surfactant-templated USY with CTAB. Argon $(87 \mathrm{~K})$ and nitrogen $(77 \mathrm{~K})$ adsorption/desorption isotherms (A). NLDFT pore-size distributions calculated from the argon $(87 \mathrm{~K})$ and nitrogen $(77 \mathrm{~K})$ isotherms $(\mathrm{B})$. Argon adsorption isotherms at $77 \mathrm{~K}$ and $65 \mathrm{~K}(\mathrm{C})$. Hysteresis scanning isotherms on the argon (77 $\mathrm{K}$ ) isotherm (D). Reprinted with permission from ref. 117. 


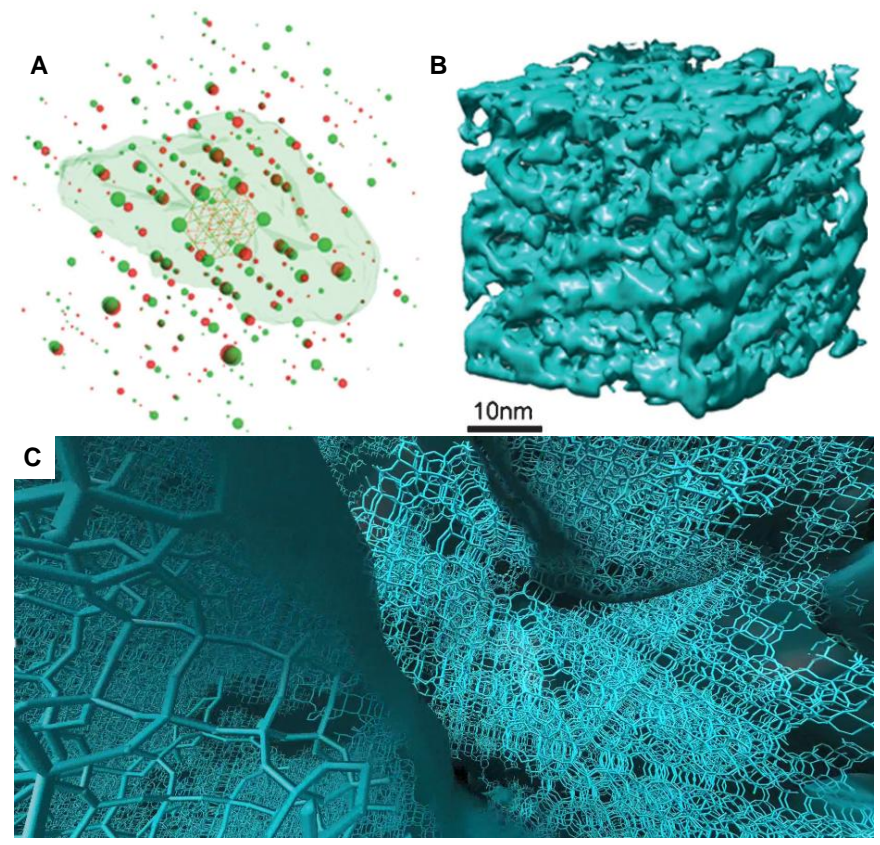

Figure 16. Rotation electron diffraction (RED) and electron tomography (ET) were used to investigate the intracrystalline mesoporous nature of surfactant-templated Y zeolite. Reconstructed 3D reciprocal lattices from the RED data with the reconstructed 3D morphology of the corresponding particle obtained from electron tomography superimposed (A). RED data shows that the particle is highly crystalline zeolite $\mathrm{Y}$ with two twin domains (lattices shown in red and green, respectively) sharing a common [111] axis. 3D reconstruction of a portion of a tomogram of mesoporous Y zeolite (B). Frame of the video of the combination of RED and ET (C). Reprinted with permission from ref. 117. 


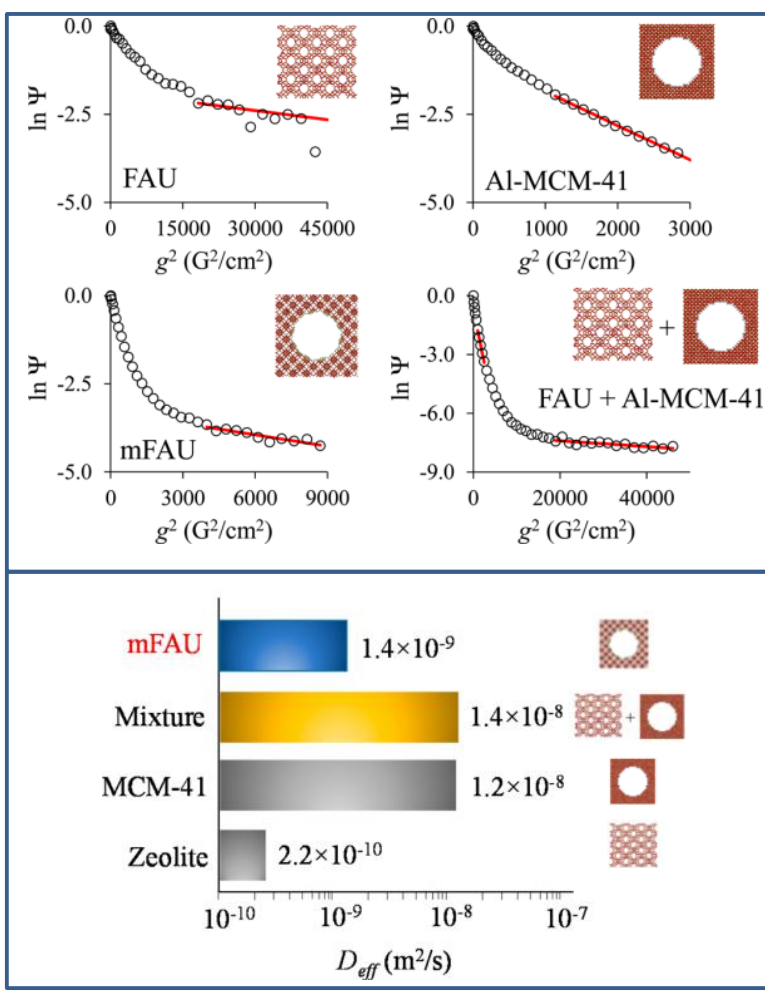

Figure 17. Top: Attenuation $\Psi$ of the spin echo signal as a function of the gradient strength $g$ measured from PFG NMR for hexane adsorbed in FAU, Al-MCM-41, mFAU (i.e. surfactant-templated USY zeolite), and a mechanical mixture of FAU + Al-MCM41. Bottom: Representation of the effective diffusivity $D_{\text {eff }}$ as determined from PFG NMR for hexane adsorbed at $298 \mathrm{~K}$ in FAU, Al-MCM-41, mFAU, and a mechanical mixture of FAU + Al-MCM-41. Adapted with permission from ref. 118. 

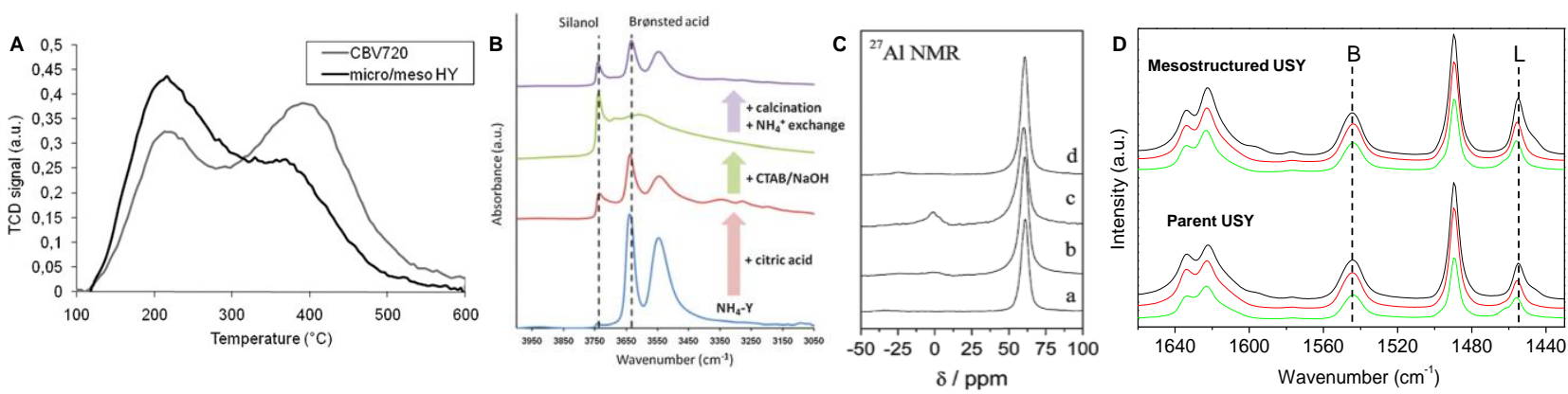

Figure 18. TPD-NH 3 profiles of parent USY (gray) and mesostructured USY (black) (A). FT-IR spectra of Y zeolite sampled along surfactant-templating (B). ${ }^{27} \mathrm{Al}$ MAS NMR of parent Na-Y zeolite (a), after acid pre-treatment (b), after surfactant-templating in the presence of CTAB and $\mathrm{NH}_{4} \mathrm{OH}$ solution (c) and after surfactant-templating in the presence of CTAB and $\mathrm{NaOH}$ solution (C). FT-IR spectra of pyridine chemisorbed parent USY and mesostructured USY recorded after desorption at $150{ }^{\circ} \mathrm{C}$ (black), 250 ${ }^{\circ} \mathrm{C}$ (red) and $350{ }^{\circ} \mathrm{C}$ (green) (D). Adapted from ref. 97 and 98. 

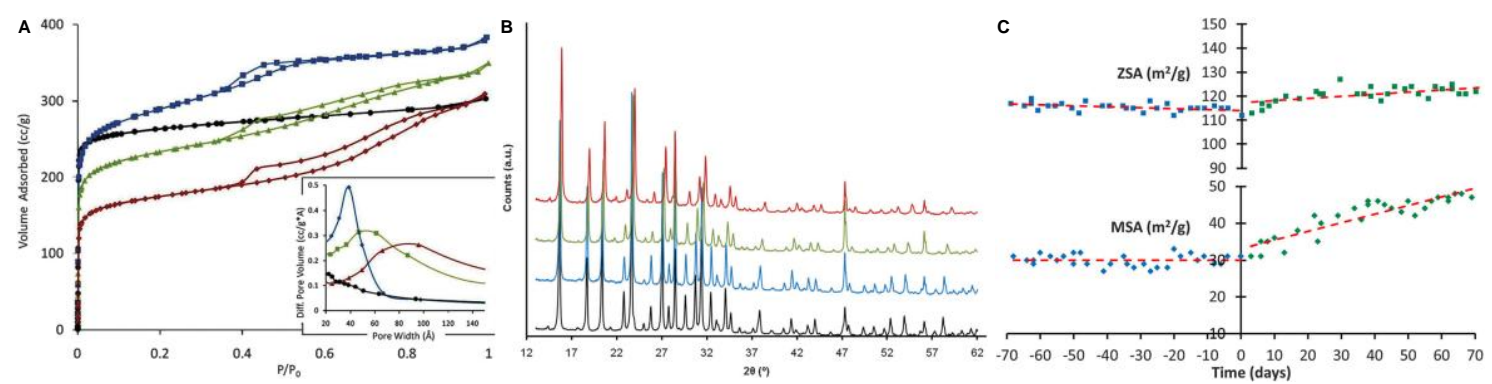

Figure 19. Ar adsorption isotherm at $87 \mathrm{~K}$ of NH4-Y (black circle), mesostructured $\mathrm{Y}$ (blue square), and mesostructured USY before (green triangle) and after (red diamond) deactivation at $7881 \mathrm{C}$ in $100 \%$ steam for 4 hours (A). The corresponding BJH pore size distributions of these samples are shown in the inset. XRD patterns of, from bottom to top, the starting NH4-Y (CBV300), mesostructured Y, the mesostructured USY, and after its deactivation at $788^{\circ} \mathrm{C}$ in $100 \%$ steam for $4 \mathrm{~h}(\mathrm{~B})$. The intensities of the last three samples were corrected using a 1.45 empirical factor to account for the radiation absorption by the rare earth oxides (5 wt\%) in these materials. Zeolite surface area (ZSA, squares) and mesopore surface area (MSA, diamonds) of the equilibrium catalyst samples gathered from CountryMark Refinery FCC Unit every 2-3 days before (blue) and after (green) the trial started at day $0(\mathrm{C})$. Reprinted with permission from ref. 97 and 124. 


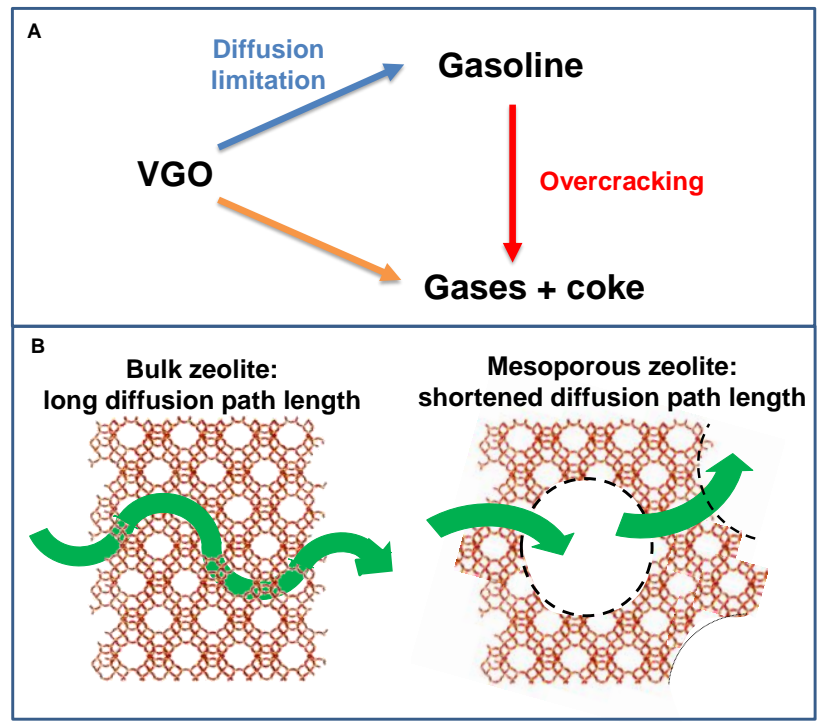

Figure 20. Three-lump model of the catalytic cracking of vacuum gas oil (VGO) (A). In a diffusion limited reaction, overcracking reactions are favored, leading to reduced conversions towards gasoline and LCO and increased selectivity towards undesired light gases and coke. Schematic representation of the diffusion path length in bulk zeolites and in hierarchical zeolites featuring intracrystalline mesoporosity (B). 

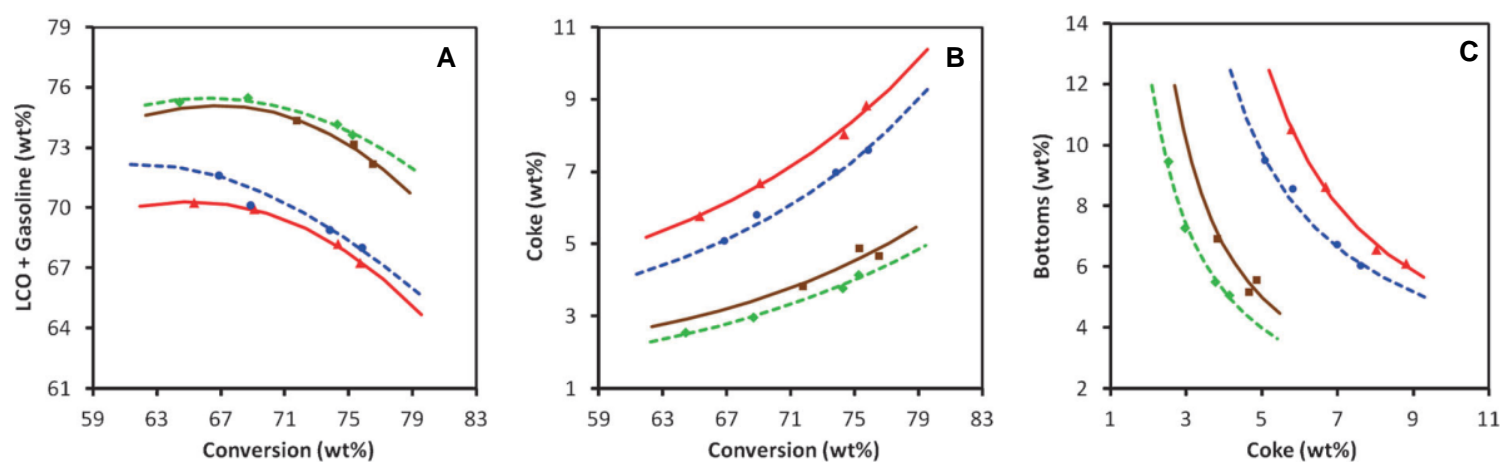

Figure 21. Advanced cracking evaluation (ACE) testing results of two FCC catalysts containing mesostructured USY zeolite to two state-of-the-art catalysts with conventional USY using two different North American refinery feeds. Light VGO feed: FCC catalyst containing mesostructured USY zeolite (green) and Conventional FCC catalyst (brown). Heavy VGO feed: FCC catalyst containing mesostructured USY zeolite (blue) and Conventional FCC catalyst (red). LCO + Gasoline yields vs. Conversion (A). Coke yields vs. Conversion (B). Bottoms yields vs. coke yields (C). Reprinted with permission from ref. 117. 


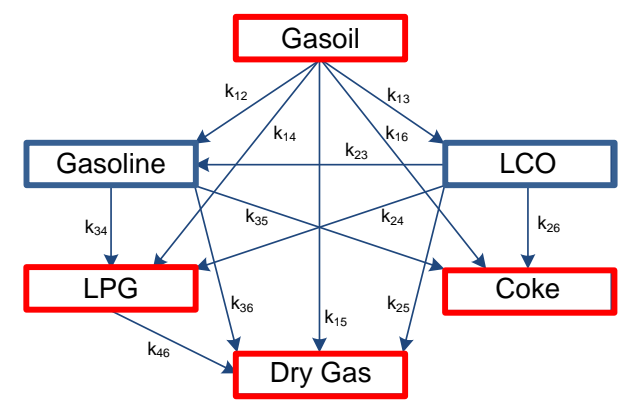

Increases in presence of intracrystalline mesoporosity

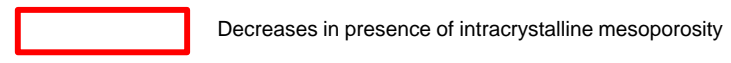

Figure 22. Six-lump model of the conversion of gasoil. Shortening the diffusion path length in zeolites leads to significant increase in the yield of the desired products (blue) and a decrease in the undesired products (red). 

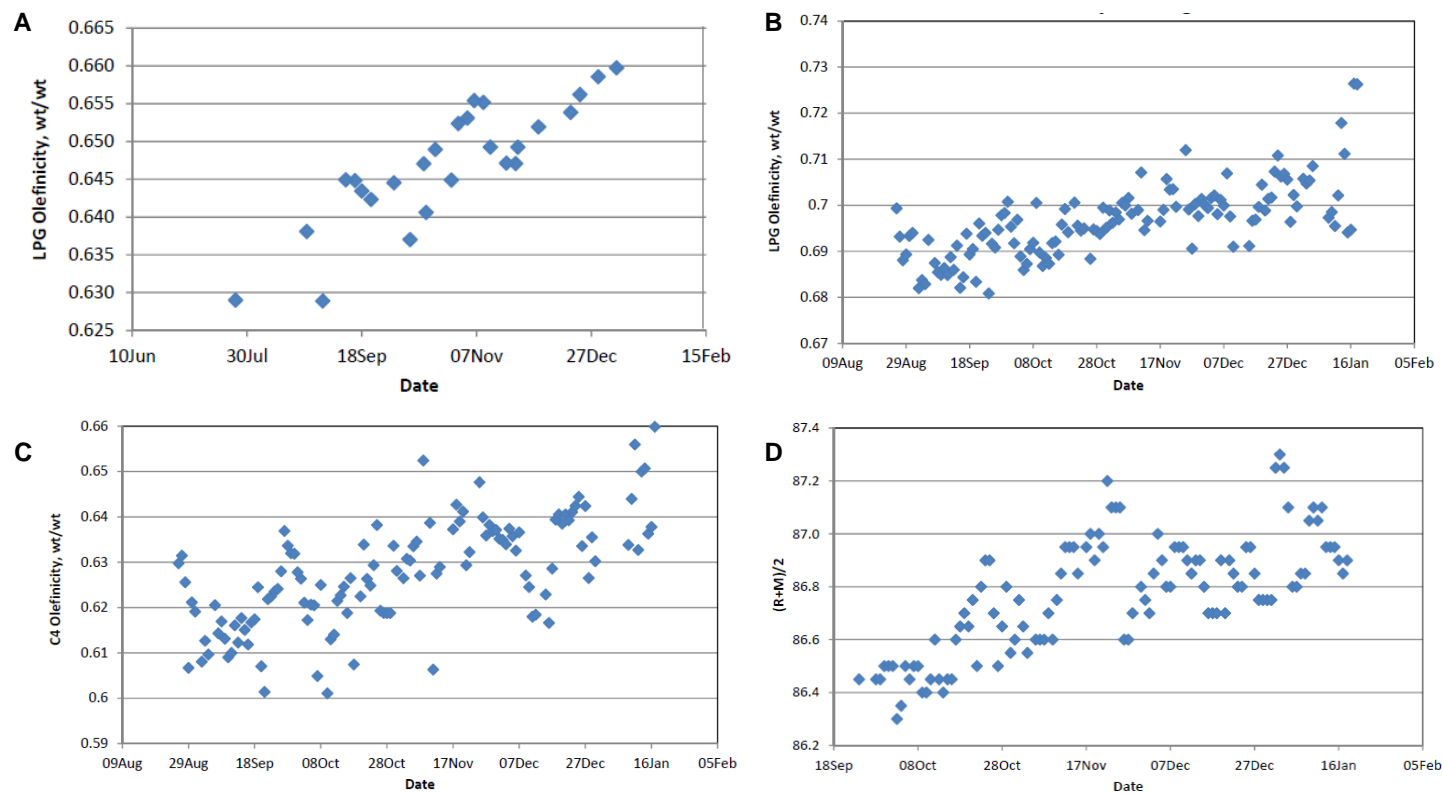

Figure 23. Evolution of LPG olifinicity during a commercial operation obtained in an ACE unit using Ecat from the refinery. Refinery data as the trail evolved on LPG olefinicity (B) $\mathrm{C}_{4}$ olefinicity (C) and gasoline octane (D). Adapted with permission from ref. 133. 
A
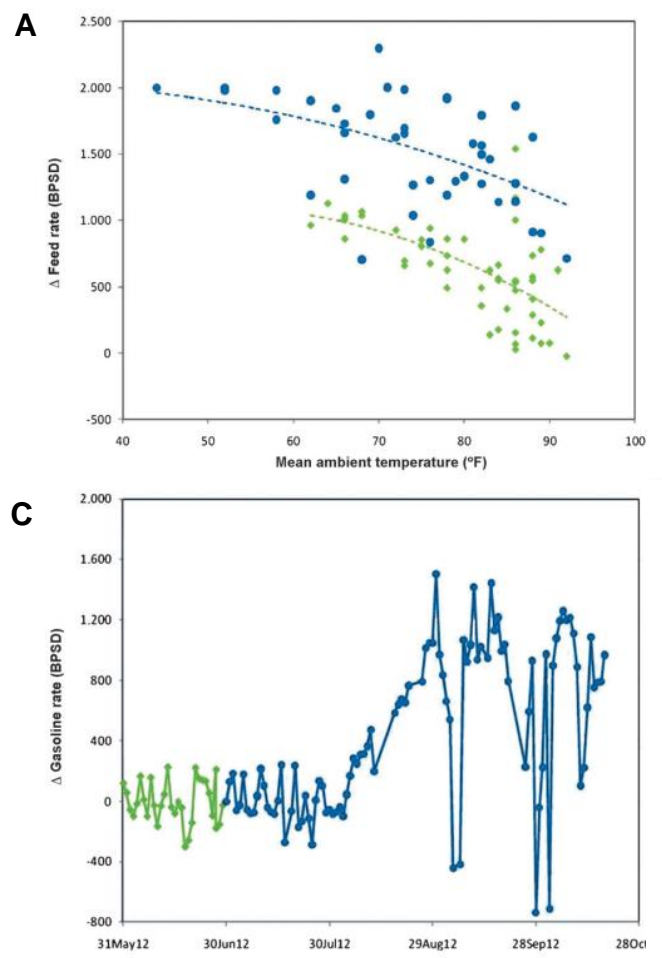
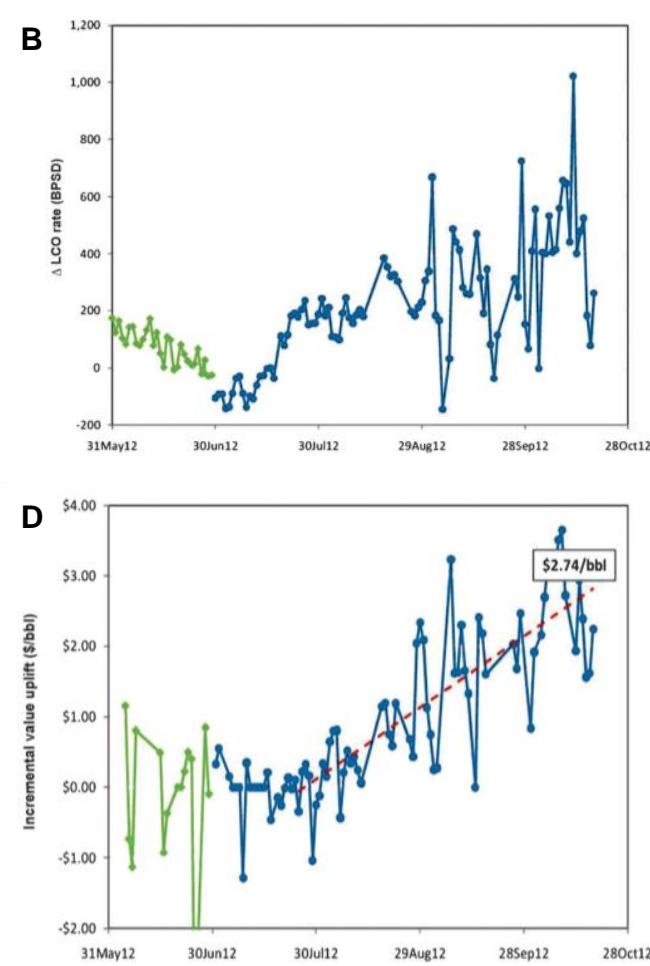

Figure 24. Observed trends during a trial at Alon's Big Spring, Texas refinery: a) Increased feed rate by 700 BPSD (barrel per stream day); b, c) increased production of gasoline and LCO (the big spikes in the plant data were owing to process interruptions and not to the catalyst); d) an incremental value uplift owing to the change-out of the incumbent catalyst for the FCC catalyst containing mesostructured Y zeolite. Adapted with permission from ref. 134. 
Graphical Abstract

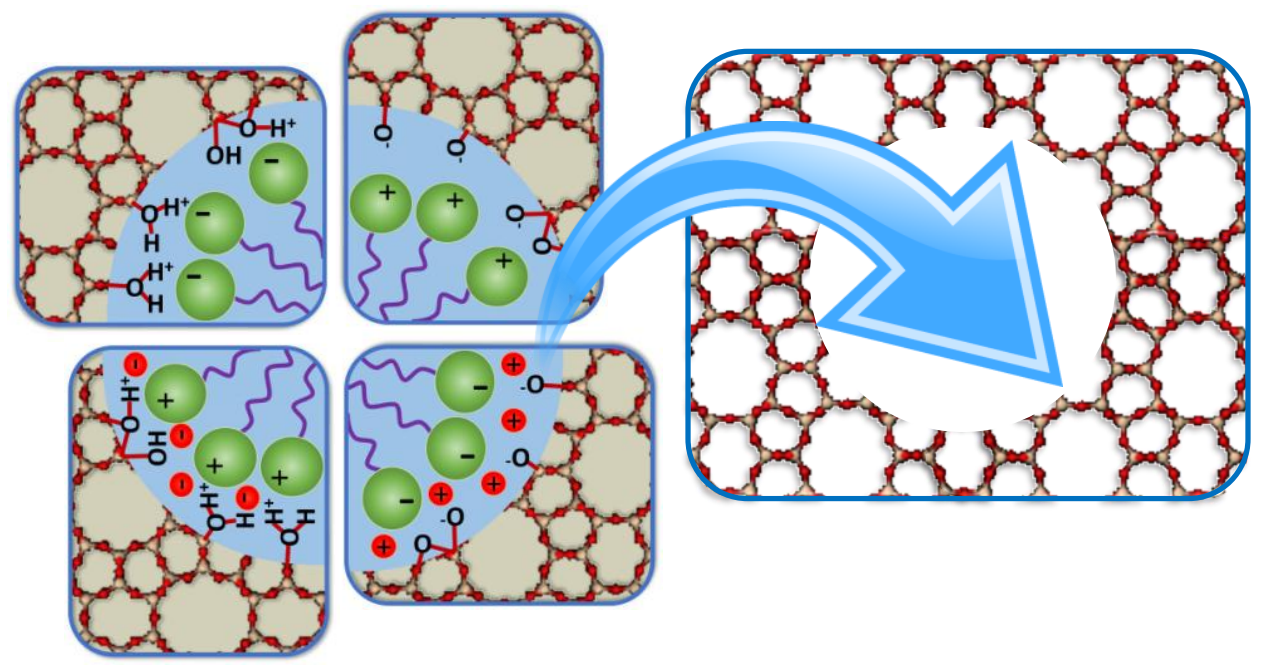

